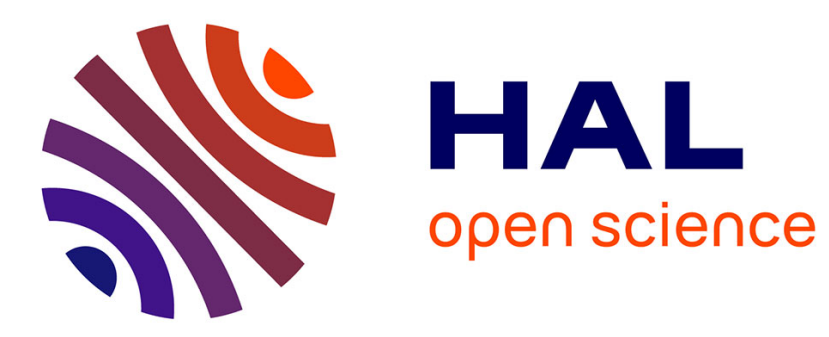

\title{
Nonexclusive competition in the market for lemons
}

\author{
Andrea Attar, Thomas Mariotti, François Salanie
}

\section{To cite this version:}

Andrea Attar, Thomas Mariotti, François Salanie. Nonexclusive competition in the market for lemons. Econometrica, 2011, 79 (6), pp.1869-1918. 10.3982/ECTA8665 . hal-02651289

\section{HAL Id: hal-02651289 \\ https://hal.inrae.fr/hal-02651289}

Submitted on 29 May 2020

HAL is a multi-disciplinary open access archive for the deposit and dissemination of scientific research documents, whether they are published or not. The documents may come from teaching and research institutions in France or abroad, or from public or private research centers.
L'archive ouverte pluridisciplinaire HAL, est destinée au dépôt et à la diffusion de documents scientifiques de niveau recherche, publiés ou non, émanant des établissements d'enseignement et de recherche français ou étrangers, des laboratoires publics ou privés. 


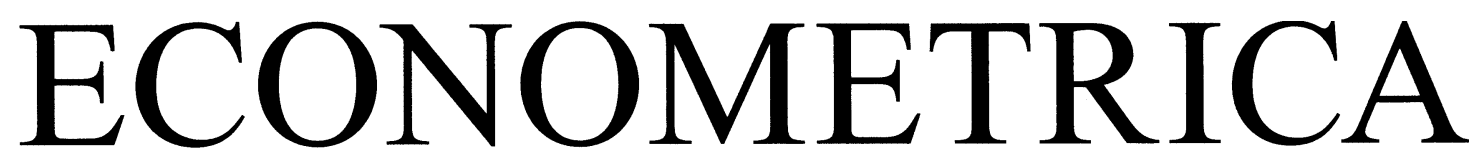

JOURNAL OF THE ECONOMETRIC SOCIETY

An International Society for the Advancement of Economic

Theory in its Relation to Statistics and Mathematics

http://www.econometricsociety.org/

Econometrica, Vol. 79, No. 6 (November, 2011), 1869-1918

NONEXCLUSIVE COMPETITION IN THE MARKET FOR LEMONS

ANDREA ATTAR

Toulouse School of Economics (IDEI, PWRI), Université Toulouse 1 Capitole, 31000 Toulouse, France, and Università degli Studi di Roma "Tor Vergata," 00133 Roma, Italy

THOMAS MARIOTTI

Toulouse School of Economics (CNRS, GREMAQ, IDEI), Université Toulouse

1 Capitole, 31000 Toulouse, France

FRANÇOIS SALANIÉ

Toulouse School of Economics (INRA, LERNA, IDEI), Université Toulouse 1

Capitole, 31000 Toulouse, France

The copyright to this Article is held by the Econometric Society. It may be downloaded, printed and reproduced only for educational or research purposes, including use in course packs. No downloading or copying may be done for any commercial purpose without the explicit permission of the Econometric Society. For such commercial purposes contact the Office of the Econometric Society (contact information may be found at the website http://www.econometricsociety.org or in the back cover of Econometrica). This statement must be included on all copies of this Article that are made available electronically or in any other format. 


\title{
NONEXCLUSIVE COMPETITION IN THE MARKET FOR LEMONS
}

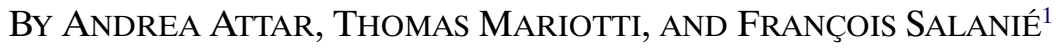 \\ A seller can trade an endowment of a perfectly divisible good, the quality of which \\ she privately knows. Buyers compete by offering menus of nonexclusive contracts, so \\ that the seller can privately trade with several buyers. In this setting, we show that an \\ equilibrium exists under mild conditions and that aggregate equilibrium allocations are \\ generically unique. Although the good for sale is divisible, in equilibrium the seller ends \\ up trading her whole endowment or not trading at all. Trades take place at a price equal \\ to the expected quality of the good, conditional on the seller being ready to trade at that \\ price. Our model thus provides a novel strategic foundation for Akerlof's (1970) results. \\ It also contrasts with competitive screening models in which contracts are assumed to \\ be exclusive, as in Rothschild and Stiglitz (1976). Latent contracts that are issued but \\ not traded in equilibrium play an important role in our analysis.
}

KEYWORDS: Adverse selection, competing mechanisms, nonexclusivity.

\section{INTRODUCTION}

A FUNDAMENTAL REASON why markets can fail is that the quality of the goods for sale is privately known by the sellers who offer them. In such a case, buyers may be concerned by the fact that, at any given price, only sellers of low quality goods are ready to trade. Despite the growing role of institutions such as certification or rating agencies, it is widely believed that this adverse selection phenomenon still represents a major obstacle to the efficient functioning of financial, insurance, and second-hand markets.

Two main approaches have been proposed to model markets prone to adverse selection. In Akerlof (1970), nondivisible goods of uncertain quality are traded on a market where privately informed sellers and uninformed buyers act as price takers. In the spirit of general equilibrium analysis, all trades must

\footnotetext{
${ }^{1}$ We thank a co-editor and three anonymous referees for very thoughtful and detailed comments. We also thank Bruno Biais, Felix Bierbrauer, Alberto Bisin, Régis Breton, Arnold Chassagnon, Pradeep Dubey, John Geanakoplos, Piero Gottardi, Martin Hellwig, Philippe Jéhiel, David Martimort, Margaret Meyer, David Myatt, Alessandro Pavan, Gwenaël Piaser, Michele Piccione, Andrea Prat, Uday Rajan, Patrick Rey, Jean-Charles Rochet, Bernard Salanié, Paolo Siconolfi, Lars Stole, Roland Strausz, Balazs Szentes, and Jean Tirole for very valuable feedback. Finally, we thank seminar audiences at Banca d'Italia, Center for Operations Research and Econometrics, Einaudi Institute for Economics and Finance, London School of Economics and Political Science, Séminaire Roy, Università degli Studi di Roma "La Sapienza," Università degli Studi di Roma "Tor Vergata," University of Oxford, Wissenschaftszentrum Berlin für Sozialforschung, and Yale University, as well as conference participants at the 2008 Toulouse Workshop of the Paul Woolley Research Initiative on Capital Market Dysfunctionalities, the 2009 Bonn Workshop on Incentives, Efficiency, and Redistribution in Public Economics, the 2009 CESifo Area Conference on Applied Microeconomics, and the 2009 Toulouse Spring of Incentives Workshop for many useful discussions. Financial support from the Einaudi Institute for Economics and Finance, the European Research Council (Starting Grant 203929-ACAP), and the Paul Woolley Research Initiative on Capital Market Dysfunctionalities is gratefully acknowledged.
} 
take place at the same price, which equates supply and demand. Since rational buyers are only ready to pay for the average quality traded, sellers of high quality goods are deterred from offering them; this may in some cases lead to a complete market breakdown. ${ }^{2}$ In Rothschild and Stiglitz (1976), uninformed buyers compete by offering informed sellers contracts for different quantities of a divisible good. The strategic interactions between buyers are thus explicitly modeled. Contracts are exclusive: each seller can trade with at most one buyer, which requires that all agents' trades can be perfectly monitored at no cost. Different unit prices for different quantities emerge in equilibrium, which allows sellers to credibly communicate their private information. This leads to lower levels of trade compared to the complete information case. For instance, in the context of insurance markets, high risk agents obtain full insurance and hence sell all of their risk, while low risk agents signal their quality by selling only part of their risk and at a higher unit price.

Following Rothschild and Stiglitz (1976), most theoretical and applied contributions to the literature on competition under adverse selection have considered frameworks in which contracts are exclusive. This assumption is sometimes appropriate: for instance, in the case of car insurance, the law typically forbids agents to take out multiple policies on a single vehicle. However, there are also many markets where exclusivity is not enforceable, usually because little information is available about the agents' trades. Competition on financial markets is often nonexclusive, as each agent can trade with multiple partners who cannot monitor each others' trades with the agent. Over-the-counter markets, where little information on trading volumes or on the net position of counterparties is publicly available, are a case in point. Other examples include the U.S. credit card industry (Rysman (2007)), the U.S. life insurance market (Cawley and Philipson (1999)), and the U.K. annuity market (Finkelstein and Poterba $(2002,2004))$. Moreover, as the case of over-the-counter markets suggests, trades on nonexclusive markets are not restricted to take place at the same unit price. Hence, a theory of nonexclusive competition should allow for arbitrary trades and avoid a priori restrictions such as linear pricing. Finally, to represent interactions in markets with a fixed number of participants, such a theory should also be of a strategic nature. Consistent with these features, this paper is an attempt to understand the impact of adverse selection in a strategic environment where buyers compete through nonexclusive contracts for the purchase of a divisible good.

Specifically, we consider the following simple model of trade. A seller endowed with a given quantity of a good may trade it with a finite number of buyers. The seller and the buyers have linear preferences over quantities and transfers exchanged. In line with Akerlof (1970), the quality of the good is the

\footnotetext{
${ }^{2}$ To ease the exposition, we implicitly assume in this introduction that the quality of a good from a buyer's point of view and the opportunity cost for a seller of giving away this good move together. The formal analysis in the remainder of the paper does not rely on such an assumption.
} 
seller's private information. Unlike in his model, and in line with Rothschild and Stiglitz (1976), the good is assumed to be perfectly divisible, so that the seller can trade any fraction of her endowment. Buyers are strategic and compete by simultaneously offering menus of bilateral contracts or, equivalently, price schedules: in particular, there is no presumption that all trades take place at the same unit price. After observing the menus offered and conditional on her private information, the seller decides which contracts to trade. Unlike in Rothschild and Stiglitz (1976), competition is nonexclusive: the seller can trade with several buyers, subject only to the constraint that the aggregate quantity traded does not exceed her endowment. For pedagogical purposes, we first consider a simple free-entry example with a two-type distribution of quality, which affords an intuitive geometric illustration of our arguments. We then turn to the case of a general distribution of quality, which offers a more flexible framework for applications. In this context, we aim to answer the following questions: Does an equilibrium always exist? Are equilibrium allocations uniquely determined? Do different types of the seller end up trading different allocations? At which prices do trades take place? What menus of contracts are required to sustain an equilibrium?

As a contrast to our results, it is useful to consider what would happen in this environment if buyers were to compete in menus of exclusive contracts. In that case, the analysis and the predictions of the model are in line with those in Rothschild and Stiglitz (1976). First, equilibria, whenever they exist, are separating: the seller can credibly signal the quality of the good she offers by trading only part of her endowment. Hence, fractional trades are a necessary feature of equilibrium, despite the linearity of preferences. Second, the very existence of an equilibrium is problematic. When quality has a two-type distribution, pure strategy equilibria exist if and only if the probability that the good is of low quality is high enough. When quality is continuously distributed, pure strategy equilibria fail to exist under very weak assumptions on the buyers' preferences. $^{3}$

The analysis of the nonexclusive competition game yields strikingly different results. First, pure strategy equilibria exist for a large class of quality distributions that includes all continuous distributions with bounded support. Next, aggregate equilibrium allocations are generically unique and feature no fractional trades: the seller trades her whole endowment if quality is low enough and otherwise does not trade at all. These allocations can be supported by simple menu offers. For instance, there always exists an equilibrium in linear price schedules, whereby each buyer offers to purchase any quantity at the same unit price. This price is equal to the expectation of the quality of the good, conditional on the seller being ready to trade at that price. While nonlinear price

\footnotetext{
${ }^{3}$ See Attar, Mariotti, and Salanié (2009, Proposition 7) for a precise statement. That the nonexistence problem is particularly severe when the seller's private information is continuously distributed is in line with Riley $(1985,2001)$.
} 
schedules are also consistent with equilibrium, this price turns out to be the unit price of any contract traded in any equilibrium. That all trades take place at the same unit price is therefore not an assumption, but rather a consequence of our analysis. Consequently, all equilibria have the Bertrand-like feature that buyers earn zero expected profits, regardless of their number.

These results are of course in line with Akerlof's (1970) classic study of the market for lemons, for which they provide a novel strategic foundation. It is therefore worth stressing the distinctive features of our model. First, the seller can trade any fraction of her endowment (divisibility). Second, contracting between the buyers and the seller is bilateral, and the seller can simultaneously trade with several buyers (nonexclusivity). Third, there is a finite number of strategic buyers (imperfect competition). Fourth, buyers can offer arbitrary menus of contracts (price schedules). Along with the simplicity of its predictions, these assumptions make the model applicable to a rich variety of situations. In particular, we show that under private bilateral contracting, our results carry over to the case where there are several sellers, as in Akerlof (1970).

An important insight of our analysis is that nonexclusivity has two consequences for the set of deviations that are available to any given buyer. On the one hand, nonexclusivity tends to expand this set, as the buyer may choose to complement the other buyers' offers by proposing that the seller trade an additional quantity. We call this behavior pivoting, and paradoxically it allows each buyer to benefit from the aggressive offers of his competitors. Compared to the exclusive case, in which pivoting is ruled out by assumption, this tends to mitigate competition. For instance, such deviations prevent one from supporting the usual Rothschild and Stiglitz (1976) allocation in equilibrium. On the other hand, nonexclusivity also gives the other buyers more instruments to block deviations. This makes it difficult to design one's menu offer so as to attract the seller precisely when the quality of the good she offers lies in some target set. Suppose, for instance, that the equilibrium price is low, so that high quality endowments are not traded, and that some buyer attempts to deviate and purchase only these. To attract a seller of a high quality good, this cream-skimming deviation must involve trading a relatively small quantity at a relatively high price. However, this contract becomes also attractive to the seller of a low quality good if, along with it, she can also trade the remaining part of her endowment with the other buyers at the equilibrium price. Thus, cream-skimming deviations can be blocked by latent contracts, that is, contracts that are not traded in equilibrium, but which the seller may want to trade at the deviation stage. As the above example suggests, these latent contracts need not be complex or exotic: in the linear price schedule equilibrium, all the latent contracts are issued at the equilibrium price. We show that, in general, many contracts need to be issued to support the equilibrium allocations. This is particularly striking when the distribution of quality is discrete, since then only finitely many contracts are effectively traded, while infinitely many latent contracts must be issued. In particular, no equilibrium can in this case be sustained through direct mechanisms. 


\section{Related Literature}

Pauly (1974) and Jaynes (1978) were the first authors to analyze competition through nonexclusive contracts in markets prone to adverse selection. Pauly (1974) stressed that Akerlof-like outcomes typically prevail in insurance markets where intermediaries are restricted to post linear price schedules. Jaynes (1978) showed that the separating equilibria characterized by Rothschild and Stiglitz (1976) are vulnerable to entry by an intermediary proposing additional trades that could be concealed from the rest of the industry. In addition, he argued that the nonexistence problem identified by Rothschild and Stiglitz (1976) can be overcome if the sharing of information about agents is explicitly modeled as part of the game among intermediaries. ${ }^{4}$

This paper is also closely related to the literature on common agency, in which competing principals deal with a privately informed agent. Following Stole (1990) and Martimort (1992), a number of recent contributions used mechanism design techniques to construct equilibrium allocations in common agency games with incomplete information..$^{5}$ The basic idea of this approach is that, given a profile of menus offered by his competitors, the best response of each principal can be computed by focusing on simple menu offers that correspond to direct revelation mechanisms. In practice, however, this best response can be effectively characterized only to the extent that the agent's indirect utility function that represents her preferences in her relationship with this principal satisfies certain regularity conditions. These conditions, such as continuity and single crossing, are robustly violated in our model, because we impose no a priori structure on the menus offered by the buyers and because the seller faces a capacity constraint. As a result, the above methodology does not apply. Instead, we derive restrictions on candidate equilibrium allocations by testing them against a set of well chosen deviations. Remarkably, this procedure allows us to obtain a full characterization of aggregate equilibrium allocations.

Biais and Mariotti (2005) constructed a linear price schedule equilibrium for a version of our nonexclusive trading game, in which gains from trade arise because the seller is more impatient than the buyers. They focused on the particular case where the unconditional average value of the good for the buyers is equal to the highest possible value of the good for the seller. This nongeneric situation arises endogenously in a model where the seller is the issuer of a security, which she can optimally design ex ante. By contrast, our analysis is general in that we allow for a large class of quality distributions and offer a full characterization of aggregate equilibrium allocations, which are shown to be generically unique.

\footnotetext{
${ }^{4}$ See Hellwig (1988) for a discussion of the relevant extensive form for the interfirm communication game.

${ }^{5}$ See, for instance, Biais, Martimort, and Rochet (2000), Martimort and Stole (2003, 2009), Calzolari (2004), Laffont and Pouyet (2004), or Khalil, Martimort, and Parigi (2007).
} 
Another related paper in the common agency literature is Biais, Martimort, and Rochet (2000), who studied a financial market in which uninformed market-makers compete in a nonexclusive way by supplying liquidity to an informed insider. Unlike the seller in our model, the insider has strictly convex preferences and faces no capacity constraint. Using the methodology outlined above, Biais, Martimort, and Rochet (2000) constructed an equilibrium in which market-makers post convex price schedules and that is unique within that class. ${ }^{6}$ One of the main features of this equilibrium is that each marketmaker is indispensable in providing utility to the insider; as a result, marketmakers end up earning strictly positive profits. This makes this equilibrium rather different from those we characterize in our setting: indeed, using a pivoting argument, we show that no buyer is ever indispensable, as the aggregate equilibrium allocations must remain available to the seller in the hypothetical case where some buyer would withdraw his menu offer. Hence, our results hold regardless of the number of competing buyers. Another difference is that all trades take place at the same unit price in any equilibrium of our model. We postpone until Section 5.2 a detailed analysis of the relationships between these two trading environments.

The importance of latent contracts as a strategic device to sustain equilibria has been mainly emphasized in moral hazard environments. ${ }^{7}$ Hellwig (1983) and Arnott and Stiglitz (1991) argued that latent contracts play the role of threats to deter entry in insurance markets where agents' effort decisions are not contractible. As a result, positive profits for active intermediaries typically arise in equilibrium. These intuitions have been extended by Bizer and DeMarzo (1992) and Kahn and Mookherjee (1998) to situations where intermediaries act sequentially, while the equilibrium features of latent contracts and the corresponding welfare implications have been further examined by Bisin and Guaitoli (2004) and Attar and Chassagnon (2009). A key insight of our analysis is that latent contracts can also be used to deter cream-skimming deviations in adverse selection environments.

Ales and Maziero (2009) studied a model of nonexclusive competition where workers privately informed about their labor productivity shocks insure their idiosyncratic risk by contracting with several insurance companies. Unlike in our model, in which the seller's participation decisions are made at the interim stage, workers choose the firms from whom they will purchase insurance ex ante, before any uncertainty is realized. Then, in any of the following periods, they observe their current productivity shocks and make their consumption and labor decisions. Firms compete at date zero by offering menus of contracts for each relevant period. Productivity shocks have no impact on their profits. This

\footnotetext{
${ }^{6}$ Piaser (2006) showed that, given these restrictions, this equilibrium can actually be sustained through direct revelation mechanisms.

${ }^{7}$ See, however, Piaser (2010) for a general discussion of the role of latent contracts in adverse selection environments.
} 
private value assumption stands in sharp contrast to the analysis developed in the present paper, where, as in Akerlof (1970), the quality of the seller's good directly affects the buyers' profits. It notably implies that firms have no incentive to attract a strict subset of workers' types by using cream-skimming deviations. As a result, firms are effectively engaged in Bertrand-like price competition. Ales and Maziero (2009) showed that the only aggregate equilibrium allocation involves no wealth redistribution between different types of workers and that it can be supported by linear price schedules. In contrast to our results, no worker is excluded from trade and firms earn zero profit on each traded contract, which rules out cross-subsidization. Latent contracts play a role in sustaining the equilibrium, as they guarantee that firms cannot unilaterally gain by redistributing wealth from productive to unproductive workers.

An alternative approach to the study of nonexclusive competition under adverse selection has been suggested by Bisin and Gottardi $(1999,2003)$ in the context of general equilibrium analysis. They focused on situations where none of the agents' trades can be monitored. As a consequence, the terms of each contract must be independent of the exchanges made in every market, which forces prices to be linear. When this restriction is postulated, competitive equilibria may fail to exist in robust circumstances. To restore existence, some nonlinearity in prices or, equivalently, some observability of trades must be reintroduced in the model. This can be achieved through bid-ask spreads (Bisin and Gottardi (1999)) or entry fees (Bisin and Gottardi (2003)). By contrast, the present paper starts from the alternative assumption that buyers can commit to arbitrary menu offers, which we see as a natural feature of competition in contracts.

The paper is organized as follows. Section 2 describes the model. In Section 3, we analyze a two-type example of our model under free entry. Section 4 provides a detailed analysis of the general model with an arbitrary distribution of quality. In Section 5, we discuss the robustness of our results, showing in particular that they extend to the case of several sellers. Section 6 concludes.

\section{NONEXCLUSIVE TRADE UNDER ADVERSE SELECTION}

\subsection{The Model}

There are two kinds of agents: a single seller, and a finite number of identical buyers indexed by $i=1, \ldots, n$, where $n \geq 2$. The seller has an endowment consisting of one unit of a perfectly divisible good that she can trade with one or several buyers. Let $q^{i}$ be the quantity of the good purchased by buyer $i$ and let $t^{i}$ be the transfer he makes in return. Feasible trades $\left(\left(q^{1}, t^{1}\right), \ldots,\left(q^{n}, t^{n}\right)\right)$ are such that $q^{i} \geq 0$ for all $i$ and $\sum_{i} q^{i} \leq 1$. Thus, the quantity of the good purchased by each buyer must at least be zero and the sum of these quantities cannot exceed the seller's endowment. We take the latter as a technological capacity constraint to which the seller's choices are subject. Observe that, in 
contrast to quantities, we impose no a priori restrictions on the sign of transfers, which is useful for certain applications of the model, such as insurance markets.

Our specification of preferences follows Samuelson (1984) and Myerson (1985). The seller's profit from trading $(Q, T)=\left(\sum_{i} q^{i}, \sum_{i} t^{i}\right)$ in the aggregate is

$$
T-\theta Q,
$$

where $\theta$ is the seller's opportunity cost of giving away her endowment. Buyer $i$ 's profit from trading $\left(q^{i}, t^{i}\right)$ is

$$
v(\theta) q^{i}-t^{i} .
$$

Hence, the quality of the good from the buyers' point of view is measured by $v(\theta)$. Adverse selection is at its worst when $v(\theta)$ is increasing in $\theta$, since, at any given price, the seller is then ready to trade only if quality is low enough. In most of our analysis, however, and unless stated otherwise, we do not require $v(\theta)$ to be increasing in $\theta$. Gains from trade arise if $v(\theta)>\theta$ for some value of $\theta$. Observe also that there are neither efficiency gains from trading with several buyers nor externalities across buyers.

In line with Akerlof (1970), mutually beneficial trades are potentially impeded because, at the trading stage, the seller is privately informed of her opportunity cost and hence of the quality of the good. Following standard terminology, we refer to $\theta$ as the type of the seller. Denote by $\mathbf{P}$ the distribution of $\theta$, by $\mathbf{E}$ the corresponding expectation operator, and by $F$ the corresponding distribution function. We let $\underline{\theta} \equiv \inf \{\theta: F(\theta)>0\}$ and $\bar{\theta} \equiv \sup \{\theta: F(\theta)<1\}$, and we assume that $-\infty<\underline{\theta}<\bar{\theta}<\infty$. The distribution $\mathbf{P}$ may be continuous, discrete, or mixed. It will sometimes be convenient to think of any point in $[\underline{\theta}, \infty)$ as a type, even if it does not belong to the support of $\mathbf{P}$, and accordingly to define the functions $v$ and $F$ over the whole of $[\underline{\theta}, \infty)$. The function $v$ is taken to be measurable over $[\underline{\theta}, \infty)$, and bounded over the support of $\mathbf{P}$. The following assumption will be maintained throughout the paper.

\section{AssUMPTION 1: If $\theta$ is an atom of $\mathbf{P}$, then $v(\theta) \geq \theta$.}

Assumption 1 imposes no restriction on $v$ when $\mathbf{P}$ is continuous. When $\mathbf{P}$ is discrete, Assumption 1 requires that, with probability 1, there are gains from trade between the seller and the buyers. This guarantees that an equilibrium always exists under nonexclusive competition; on the contrary, one can construct examples in which no equilibrium exists if Assumption 1 fails to hold. 
Trading is nonexclusive in the sense that no buyer can contract on the trades that the seller makes with other buyers. ${ }^{8}$ Thus, as in Biais, Martimort, and Rochet (2000) or Segal and Whinston (2003), a contract describes a bilateral trade between the seller and a particular buyer; a menu is a set of such contracts. The timing of events is as follows. First, buyers compete in menus for the good offered by the seller. ${ }^{9}$ Then the seller can simultaneously trade with several buyers, subject to her capacity constraint. These two stages can be formally described as follow:

(i) Each buyer $i$ offers a menu of contracts, that is, a set $C^{i}$ of quantitytransfer pairs $\left(q^{i}, t^{i}\right) \in[0,1] \times \mathbb{R}$ that contains at least the no-trade contract $(0,0) .^{10}$

(ii) After privately learning her type $\theta$, the seller selects one contract $\left(q^{i}, t^{i}\right)$ from each of the menus $C^{i}$ offered by the buyers, subject to the constraint that $\sum_{i} q^{i} \leq 1$.

A pure strategy for the seller is a function that maps each type $\theta$ and each menu profile $\left(C^{1}, \ldots, C^{n}\right)$ into a vector of contracts $\left(\left(q^{1}, t^{1}\right), \ldots,\left(q^{n}, t^{n}\right)\right) \in$ $C^{1} \times \cdots \times C^{n}$ such that $\sum_{i} q^{i} \leq 1$. To ensure that any type $\theta$ 's profit maximization problem

$$
\max \left\{\sum_{i} t^{i}-\theta \sum_{i} q^{i}:\left(q^{i}, t^{i}\right) \in C^{i} \text { for all } i \text { and } \sum_{i} q^{i} \leq 1\right\}
$$

has a solution, we require the buyers' menus $C^{i}$ to be compact sets. The correspondence of optimal choices associated to (1) has nonempty compact values and is upper hemicontinuous with respect to $\theta$, so that it admits a measurable selection. ${ }^{11}$ Thus, we can safely assume that, for any menu profile the buyers may offer, the seller's strategy is measurable with respect to her type, which implies in turn that the buyers' expected profits are well defined mathematically. Throughout the paper, the equilibrium concept is pure strategy perfect Bayesian equilibrium.

\subsection{Applications}

Our model is basically a model of trade, with the following features: (i) a seller faces several potential buyers; (ii) the good they trade is divisible; (iii) its

${ }^{8}$ In particular, buyers cannot make transfers contingent on the whole profile of quantities $\left(q^{1}, \ldots, q^{n}\right)$ traded by the seller. This distinguishes our trading environment from a menu auction à la Bernheim and Whinston (1986).

${ }^{9}$ As established by Peters (2001) and Martimort and Stole (2002), there is no need to consider more general mechanisms in this multiple-principal single-agent setting. See also footnote 26 for the multiple-principal multiple-agent case under bilateral contracting.

${ }^{10} \mathrm{This}$ requirement allows one to deal with participation in a simple way. It reflects the fact that the seller cannot be forced to trade with any particular buyer.

${ }^{11}$ This follows, respectively, from Berge's maximum theorem and from Kuratowski and RyllNardzewski's selection theorem (Aliprantis and Border (1999, Theorems 16.31 and 17.13)). 
quality is the seller's private information; (iv) the seller may trade with several buyers; (v) the buyers cannot contract on each other's trades with the seller. It is easy to think of many markets for which (ii)-(iv) hold; (i) and (v) deserve more care. Consider first the single-seller assumption (i). While it may be suited to certain applications, many others typically involve several sellers. Our analysis remains relevant in such instances. Indeed, we show in Section 5.1 that our characterization of equilibria extends to multiple-buyer multiple-seller environments where contracting is both bilateral and private. With regard to the nonexclusivity assumption (v), it should be noted that the mere fact that an agent engages in multiple contractual relationships, as in (iv), is no evidence that trades with third parties are not contractible. With these caveats in mind, the following examples illustrate some possible applications.

\section{Financial Markets}

In a first interpretation of the model, the seller is an issuer or an underwriter attempting to raise cash by selling a security backed by some underlying assets, and the buyers are outside investors. As in DeMarzo and Duffie (1999) or Biais and Mariotti (2005), gains from trade may arise in this context even if all parties are risk neutral, provided the issuer discounts future cash flows at a higher rate than investors do; this may reflect credit constraints or, in the financial services industry, binding minimum capital requirements. In this case, the marginal cost of the security for the issuer, that is, its value to her if retained, is only a fraction of the value of the security to the investors: formally, $\theta=\delta v(\theta)$ for some discount factor $\delta \in(0,1)$. Here $Q$ is the total fraction of the security sold by the issuer, while $1-Q$ is the residual fraction of the security that the issuer retains. It is natural to assume that, at the issuing stage, the issuer has better information than the investors about the value of the underlying assets and hence about the value of the security she issues. The above specification of preferences could also be used to model trade in an over-the-counter market, where exchanges are typically bilateral and unobserved by third parties.

\section{Labor Market}

In an alternative interpretation of the model, the seller is a self-employed worker and the buyers are her clients. The worker can provide services to several clients and divide her time endowment accordingly. This is the case in legal or financial services, where a consultant commonly works on behalf of several firms or individuals; similarly, a craftsman typically has many customers and a salesman can represent different companies. In these examples, it is reasonable to assume that trades with third parties are not observable, and thus a fortiori not contractible, from the perspective of each of the worker's clients. The worker's type $\theta$ is her opportunity cost of selling one unit of her time to any given client, while $v(\theta)$ is the productivity of a worker of type $\theta$. Here $Q$ is the total fraction of time spent working, while $1-Q$ is the residual fraction of time 
that the worker can spend on leisure. This stylized labor market model differs from the one studied by Mas-Colell, Whinston, and Green (1995, Chapter 13, Section B) in that labor is divisible and competition for the worker's services is nonexclusive.

\section{Insurance Markets}

The last interpretation of our model is motivated by the fact that competition on some insurance markets, such as the U.K. annuity market, is de jure nonexclusive. The seller is a risk-averse agent and the buyers are insurance companies with whom she can trade a risk. The agent has wealth $W$ and can incur a loss $L$ with privately known probability $\xi$. An insurance contract with company $i$ consists of a reimbursement $r^{i}$ and a premium $p^{i}$. To model the agent's preferences, we rely on Yaari's (1987) dual theory of choice under risk: the agent's utility is linear in wealth but nonlinear in probabilities. As a result, the utility she derives from aggregate reimbursements $R=\sum_{i} r^{i}$ and aggregate premia $P=\sum_{i} p^{i}$ is

$$
W-P-f(\xi)(L-R),
$$

while the profit of insurance company $i$ is

$$
p^{i}-\xi r^{i}
$$

Assume that overinsurance is prohibited, so that $R$ is at most equal to $L$. Letting $t^{i} \equiv-p^{i}, q^{i} \equiv r^{i}, \theta \equiv-f(\xi)$, and $v(\theta) \equiv-\xi$ leads back to our model. Gains from trade arise in this context if, with strictly positive probability, $f(\xi)>\xi$, so that the agent puts more weight on the occurrence of a loss than insurance companies do.

\section{A TWO-TYPE EXAMPLE}

In this section, we illustrate our main results in a simplified version of our model where the seller's type can be either low, $\theta=\underline{\theta}$, or high, $\theta=\bar{\theta}$, for some $\bar{\theta}>\underline{\theta}>0$. To further simplify the exposition, we assume that the quality of the good increases with the type of the seller, that is, $v(\bar{\theta})>v(\underline{\theta})$, and that it would be efficient to trade no matter the type of the seller, that is, $\underline{v}(\underline{\theta})>\underline{\theta}$ and $v(\bar{\theta})>$ $\bar{\theta}$. Finally, to avoid trivial cases, we assume that $\nu \equiv \mathbf{P}[\theta=\bar{\theta}] \in(0, \overline{1})$. Note that this model can be interpreted as a linearized version of Rothschild and Stiglitz's (1976) model, the key difference with their setting being that competition is nonexclusive. To simplify the exposition, we focus in this section on equilibria in which at least one buyer is inactive. ${ }^{12}$ It is convenient to interpret this situation as a free-entry equilibrium in which inactive buyers are potential entrants.

\footnotetext{
${ }^{12}$ Step 1 of the proof of Proposition 2 shows that this restriction is actually inconsequential.
} 
For a given equilibrium, let $(\underline{Q}, \underline{T})$ and $(\bar{Q}, \bar{T})$ be the aggregate equilibrium allocations of the two types of the seller, which they trade with the incumbent buyers. Given that the seller's preferences over $(Q, T)$ satisfy a strict singlecrossing condition, an immediate implication of incentive compatibility is that $\bar{Q}$ cannot be higher than $Q$. If the two types of the seller trade different aggregate allocations in equilibrium, we say that the equilibrium is separating; otherwise, we say that the equilibrium is pooling. The key tool for characterizing these allocations is that an entrant may use them as a support for proposing attractive additional trades to some type of the seller, a technique we referred to as pivoting in the Introduction.

\section{Mild Adverse Selection}

Whenever $\mathbf{E}[v(\theta)]>\bar{\theta}$, adverse section is mild, in the sense that each type would be ready to sell her endowment at a price $\mathbf{E}[v(\theta)]$. We show that in this case any equilibrium must be pooling, with $(\underline{Q}, \underline{T})=(\bar{Q}, \bar{T})=(1, \mathbf{E}[v(\theta)])$. To see this, suppose that $\bar{Q}<1$ in a candidate equilibrium. Consider what happens if an entrant proposes an additional contract that allows the seller to trade the quantity $1-\bar{Q}$ at a unit price between $\bar{\theta}$ and $\mathbf{E}[v(\theta)]$. Because its unit price is more than $\bar{\theta}$, it is strictly profitable for type $\bar{\theta}$ to trade this contract on top of $(\bar{Q}, \bar{T})$. Because its unit price is less than $\mathbf{E}[v(\theta)]$, and thus a fortiori less than $v(\bar{\theta})$, this contract is profitable for the entrant whether type $\underline{\theta}$ chooses to trade it or not. This shows that if $\mathbf{E}[v(\theta)]>\bar{\theta}$, then $\bar{Q}=1$. By incentive compatibility, this implies that $Q=1$ as well; therefore, any equilibrium must be pooling, with both types trading efficiently. A standard Bertrand argument can then be used to show that $\underline{T}=\bar{T}=\mathbf{E}[v(\theta)]$ : competition bids up the price of the seller's endowment to its average value $\mathbf{E}[v(\theta)]$ for the buyers, a price at which both types are ready to trade and buyers earn zero profit.

Which menus can be used to support this outcome? We see in Proposition 2 below that whenever $\mathbf{E}[v(\theta)]>\bar{\theta}$, there exists an equilibrium in linear price schedules in which at least two buyers stand ready to buy any quantity of the good at the constant unit price $\mathbf{E}[v(\theta)]$. Let us simply indicate how such linear menu offers block one class of deviations for the buyers that has been emphasized in the literature on exclusive competition under adverse selection, namely, cream-skimming deviations targeted at type $\bar{\theta}$. In the present context, such deviations consist in proposing to type $\bar{\theta}$ to signal herself by trading a quantity less than 1 , but at a unit price above $\mathbf{E}[v(\theta)]$. On Figure 1, potentially profitable cream-skimming deviations are located in the triangle $A B C .{ }^{13}$

\footnotetext{
${ }^{13}$ Point $C$ corresponds to the aggregate equilibrium allocation of both types of the seller. The solid lines passing through $C$ are their equilibrium isoprofit lines, with slopes $\underline{\theta}$ and $\bar{\theta}$. The dotted lines passing through the origin $O$ are zero isoprofit lines for the buyers, with slopes $\mathbf{E}[v(\theta)]$ and $v(\bar{\theta})$.
} 


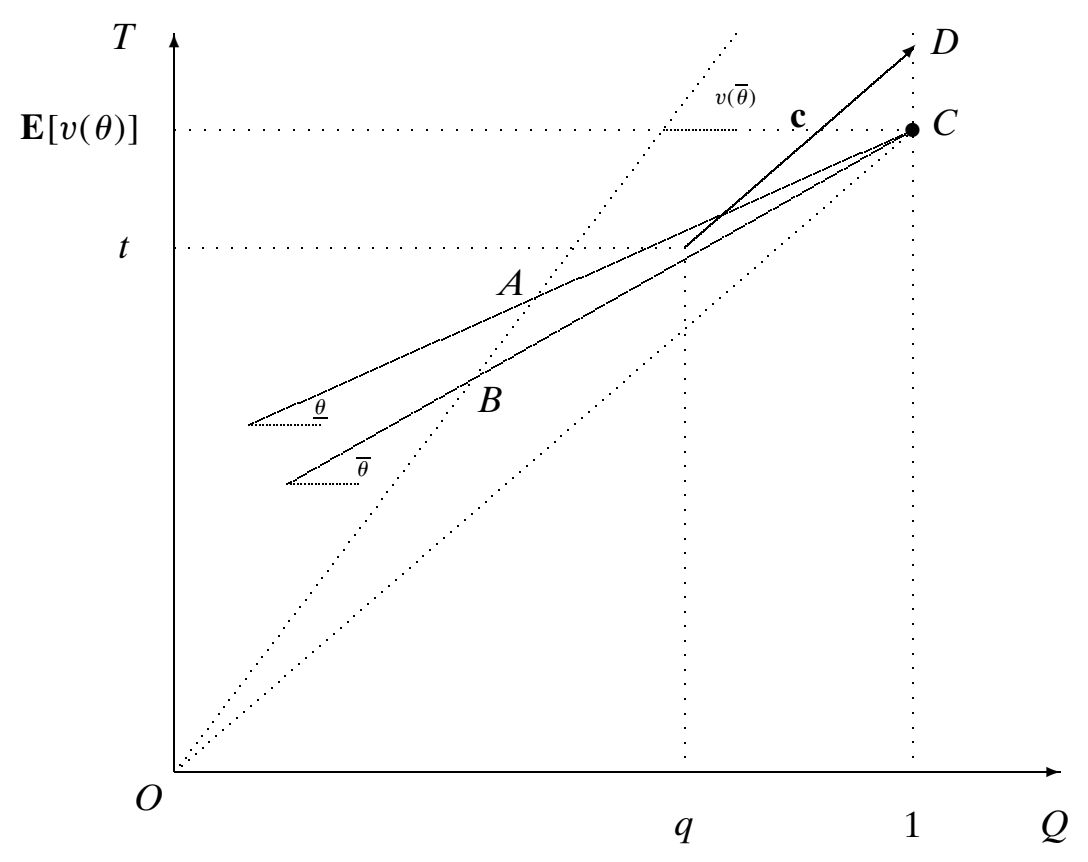

FIGURE 1.-Deterring cream-skimming deviations when $\mathbf{E}[v(\theta)]>\bar{\theta}$.

Consider one such deviation, $(q, t)$. If competition were exclusive, the contract $(q, t)$ would be traded by type $\bar{\theta}$ only and would be profitable to the buyer who would issue it. But under nonexclusive competition, and given the postulated linear menu offers, each type of the seller can combine $(q, t)$ with the contract represented by the vector $\mathbf{c}$, which allows her to trade the quantity $1-q$ at unit price $\mathbf{E}[v(\theta)]$. In this way, the seller can, irrespective of her type, reach the aggregate allocation $D$, which she prefers to her aggregate equilibrium allocation $C$. Thus, if a buyer were to issue the contract $(q, t)$, both types of the seller would trade it; since $t>\mathbf{E}[v(\theta)] q$, this buyer would make losses. This shows that cream-skimming deviations are blocked by linear price schedules with unit price $\mathbf{E}[v(\theta)]$. Proposition 2 below shows that such menu offers more generally deter any deviation.

\section{Severe Adverse Selection}

Whenever $\mathbf{E}[v(\theta)]<\bar{\theta}$, adverse selection is severe in the sense that type $\bar{\theta}$ would no longer be ready to sell her endowment at price $\mathbf{E}[v(\theta)] .^{14}$ Yet $\mathbf{E}[v(\theta)]$ is the maximum price the buyers would be ready to pay for the seller's endowment, assuming that both types trade. Thus, a pooling equilibrium is impossible

\footnotetext{
${ }^{14}$ The nongeneric case where $\mathbf{E}[v(\theta)]=\bar{\theta}$ is briefly discussed after Proposition 2.
} 
and any equilibrium must be separating, with $\bar{Q}<Q$. We first argue that, as under mild adverse selection, type $\underline{\theta}$ must trade efficiently in equilibrium, that is, $Q=1$. To see this, suppose that $Q<1$ in a candidate equilibrium. Consider what happens if an entrant proposes an additional contract allowing the seller to trade the quantity $1-\underline{Q}$ at a unit price between $\underline{\theta}$ and $v(\underline{\theta})$. Because its unit price is more than $\underline{\theta}$, it is strictly profitable for type $\underline{\theta}$ to trade this contract on top of $(\underline{Q}, \underline{T})$. Because its unit price is less than $v(\underline{\theta})$, and thus a fortiori less than $v(\bar{\theta})$, this contract is profitable for the entrant whether type $\bar{\theta}$ chooses to trade it or not. This shows that one must have $Q=1$ in equilibrium.

Let us now examine the aggregate quantity $\bar{Q}<1$ traded by type $\bar{\theta}$ in equilibrium. Define $p \equiv(\underline{T}-\bar{T}) /(1-\bar{Q})$ to be the slope of the line segment connecting the points $(\bar{Q}, \bar{T})$ and $(1, \underline{T})$. That is, $p$ is the implicit unit price at which the quantity $1-\bar{Q}$ can be sold to move from $(\bar{Q}, \bar{T})$ to $(1, \underline{T})$. By incentive compatibility, $p$ must lie between $\underline{\theta}$ and $\bar{\theta}$. Yet a key feature of nonexclusivity is that equilibrium imposes a tighter lower bound on $p$. Indeed, we now show that $p$ cannot be less than $v(\underline{\theta})$. To see this, suppose that $p<v(\underline{\theta})$ in a candidate equilibrium. Consider what happens if an entrant proposes an additional contract, allowing the seller to trade the quantity $1-\bar{Q}$ at a unit price between $p$ and $v(\underline{\theta})$. Because its unit price is more than $p$, type $\underline{\theta}$ strictly prefers trading this contract on top of $(\bar{Q}, \bar{T})$ to trading $(1, \underline{T})$. Because its unit price is less than $v(\underline{\theta})$, and thus a fortiori less than $v(\bar{\theta})$, this contract is profitable for the entrant whether type $\bar{\theta}$ chooses to trade it or not. This shows that one must have $p \geq v(\underline{\theta})$ in equilibrium. Along with the fact that necessarily $\bar{T} \geq \bar{\theta} \bar{Q}$, this implies that the buyers' aggregate profit

$$
\begin{aligned}
& (1-\nu)[v(\underline{\theta})-\underline{T}]+\nu[v(\bar{\theta}) \bar{Q}-\bar{T}] \\
& \quad=(1-\nu)[v(\underline{\theta})-p(1-\bar{Q})]+\nu v(\bar{\theta}) \bar{Q}-\bar{T}
\end{aligned}
$$

is at most $\{\mathbf{E}[v(\theta)]-\bar{\theta}\} \bar{Q}$. Since equilibrium profits must at least be zero, this shows that when $\mathbf{E}[v(\theta)]<\bar{\theta}$, then $(\bar{Q}, \bar{T})=(0,0)$; therefore, type $\bar{\theta}$ is completely excluded from trade. The buyers' aggregate profit then reduces to $(1-\nu)[v(\underline{\theta})-p]$; since $p$ cannot be less than $v(\underline{\theta}), p$ must actually be equal to $v(\underline{\theta})$. It follows that buyers earn zero profit, and that $(Q, \underline{T})=(1, v(\underline{\theta}))$.

There remains to construct menus that can be used to support this outcome. We see in Proposition 2 below that whenever $\mathbf{E}[v(\theta)]<\bar{\theta}$, there exists an equilibrium in linear price schedules in which at least two buyers stand ready to buy any quantity of the good at the constant unit price $v(\underline{\theta})$. As in the mild adverse selection case, let us simply indicate how such menu offers are enough to block cream-skimming deviations targeted at type $\bar{\theta}$. In the present context, such deviations consist in proposing to type $\bar{\theta}$ to move away from the no-trade outcome by trading a relatively small quantity at a unit price above $\bar{\theta}$. 


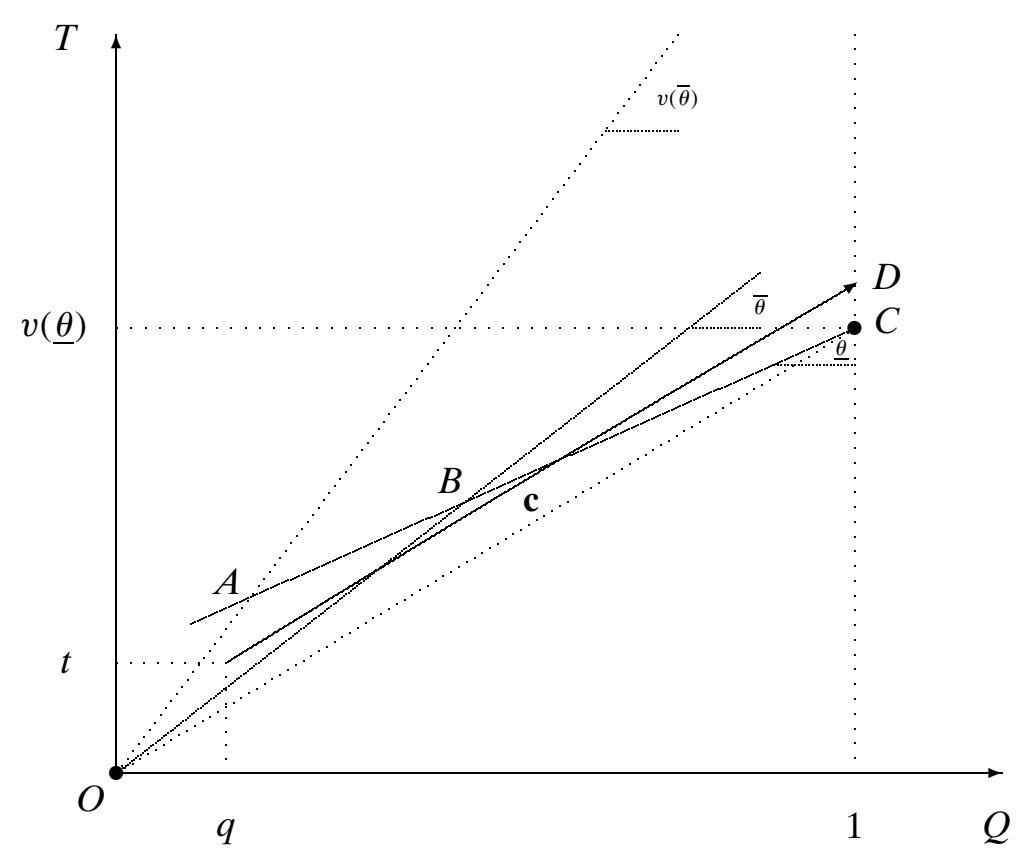

FIGURE 2.-Deterring cream-skimming deviations when $\mathbf{E}[v(\theta)]<\bar{\theta}$.

On Figure 2, potentially profitable cream-skimming deviations are located in the triangle $O A B .^{15}$

Consider one such deviation, $(q, t)$. If competition were exclusive, the contract $(q, t)$ would be traded by type $\bar{\theta}$ only and would be profitable to the buyer who would issue it. But under nonexclusive competition, and given the postulated menu offers, type $\underline{\theta}$ can combine $(q, t)$ with the contract represented by the vector $\mathbf{c}$, which allows her to trade the quantity $1-q$ at unit price $v(\underline{\theta})$. In this way, type $\underline{\theta}$ can reach the aggregate allocation $D$, which she prefers to her aggregate equilibrium allocation $C$. Thus, if a buyer were to issue the contract $(q, t)$, both types of the seller would trade it; since $t>\bar{\theta} q>\mathbf{E}[v(\theta)] q$, this buyer would make losses. This shows that cream-skimming deviations are blocked by linear price schedules with unit price $v(\underline{\theta})$. Proposition 2 below shows that such menu offers more generally deter any deviation.

The above analysis provides a new foundation for Akerlof's (1970) original results. First, if adverse selection is severe, only low quality goods are traded

\footnotetext{
${ }^{15}$ The origin $O$ corresponds to the aggregate equilibrium allocation of type $\bar{\theta}$. Point $C$ corresponds to the aggregate equilibrium allocation of type $\underline{\theta}$. The solid lines passing through $O$ and $C$ are the equilibrium isoprofit lines of types $\bar{\theta}$ and $\underline{\theta}$. The dotted lines passing through the origin $O$ are zero isoprofit lines for the buyers, with slopes $v(\underline{\theta})$ and $v(\bar{\theta})$.
} 
in equilibrium. Second, the price at which the seller can trade her endowment in equilibrium is the expectation of the quality of the good, conditional on the seller being ready to trade at that price, that is, depending on whether adverse selection is mild or severe, $\mathbf{E}[v(\theta)]$ or $v(\underline{\theta})$.

These results contrast sharply with those that would obtain if contracts were assumed to be exclusive, as in standard competitive screening models. ${ }^{16}$

First, the exclusive competition game has an equilibrium if and only if the probability that the good is of high quality is low enough, while under Assumption 1, the nonexclusive competition game always has an equilibrium, as we show below in Proposition 2.

Second, all equilibria of the exclusive competition game are separating, while under mild adverse selection, all equilibria of the nonexclusive competition game are pooling. In particular, cross-subsidies can take place under nonexclusive competition, unlike under exclusive competition.

Third, even if adverse selection is severe and thus all equilibria of the nonexclusive competition game are separating, their structure is very different from that of the separating equilibria of the exclusive competition game. In the latter case, type $\underline{\theta}$ is indifferent between her equilibrium contract and that of type $\bar{\theta}$, who trades a strictly positive fraction of her endowment. By contrast, in the former case, type $\underline{\theta}$ strictly prefers her aggregate equilibrium allocation to that of type $\bar{\theta}$, who does not trade at all. This reflects that nonexclusive competition induces a specific cost of screening the seller's type in equilibrium. Intuitively speaking, the mechanism by which type $\bar{\theta}$ can signal herself by trading a nonzero fraction of her endowment, as in the equilibria of the exclusive competition game, is shut down under nonexclusive competition. This is because type $\underline{\theta}$ could easily mimic this behavior and trade the remaining fraction of her endowment at a fair price. Therefore, only pooling outcomes or separating outcomes in which type $\bar{\theta}$ is excluded from trade emerge in equilibrium.

Fourth, our analysis suggests that to sustain an equilibrium in the nonexclusive competition game, some contracts must be issued, the goal of which is to deter cream-skimming deviations: such are, for instance, the contracts $\mathbf{c}$ depicted on Figures 1 and 2, which block the deviations $(q, t)$. Indeed, we show in Section 4.4 that under a wide array of circumstances, an infinite number of contracts must remain available if any buyer withdraws his menu offer. In the case where the agent's type space is finite, as in the example discussed in this section, this shows that most contracts are latent: they are issued only to discipline other buyers. By contrast, latent contracts are useless under exclusive competition.

\footnotetext{
${ }^{16}$ The analysis of the exclusive competition game in the two-type specification of this section is formally analogous to that of Rothschild and Stiglitz's (1976) competitive insurance model. See the Supplemental Material (Attar, Mariotti, and Salanié (2011)) for details.
} 


\section{EQUILIBRIUM ANALYSIS: THE GENERAL CASE}

We now turn to the analysis of the general model described in Section 2. Our goal is to provide a complete characterization of aggregate equilibrium outcomes, to show that an equilibrium always exists, and to identify properties of equilibrium menus. This program raises a number of theoretical issues. Indeed, from a methodological viewpoint, a standard insight for the analysis of common agency games with incomplete information is that in any pure strategy equilibrium of such a game, each principal $i$ acts like a monopolist facing an agent whose preferences are represented by an indirect profit function of $\left(\theta, q^{i}, t^{i}\right)$ that depends on the menus offered by principals $j \neq i .{ }^{17}$ Whenever this function is well behaved, which is the case under appropriate assumptions over the menus offered by principals $j \neq i$, one can apply standard mechanism design techniques to characterize the best response of principal $i$. This, however, is typically not the case in our model. The first reason is that we do not impose any conditions over the menus offered by the buyers, except that they consist of compact sets of contracts. The second reason is that the seller makes choices under a capacity constraint. Taken together, these two key features of our model imply that the seller's indirect profit function, viewed from the perspective of buyer $i$, might be discontinuous in $q^{i}$ and, furthermore, that it need not satisfy a single-crossing condition in $\left(q^{i}, t^{i}\right) .{ }^{18}$ This in turn makes it difficult to apply the standard methodology for common agency games to our nonexclusive competition game. Instead, in line with the above two-type example, we fully characterize aggregate equilibrium allocations by requesting that they survive well chosen deviations.

\subsection{The Monopsony Case}

As a preliminary, it is useful to consider the case where there is a single buyer. Suppose first that this monopsonist is constrained to use a simple fixed price contract, by means of which he offers to purchase the seller's endowment at some price $p$. Only types $\theta \leq p$ are then ready to accept this offer, with type $p$ being indifferent. If type $p$ is not an atom of $\mathbf{P}$, then her decision makes no difference to the monopsonist's profit. If type $p$ is an atom of $\mathbf{P}$, Assumption 1 implies that the monopsonist cannot make losses, and can possibly gain, from

\footnotetext{
${ }^{17}$ See, for instance, Martimort and Stole (2009) for a recent exposition of this methodology.

${ }^{18}$ This can be checked by considering the quantity $z^{-i}\left(\theta, 1-q^{i}\right)$ that represents the highest profit type $\theta$ can get from trading with buyers $j \neq i$ while selling quantity $q^{i}$ to buyer $i$; see (20) and (21). Because the menus $C^{j}$ are only requested to be compact and may, therefore, correspond to discontinuous price schedules, Berge's maximum theorem does not apply to the function $q^{i} \mapsto$ $z^{-i}\left(\theta, 1-q^{i}\right)$ : an increase in $q^{i}$ may generate a downward jump in $z^{-i}\left(\theta, 1-q^{i}\right)$. As a result, the seller's indirect profit function $\left(\theta, q^{i}, t^{i}\right) \mapsto t^{i}-\theta q^{i}+z^{-i}\left(\theta, 1-q^{i}\right)$ may fail to satisfy a singlecrossing condition, unlike the seller's profit function over aggregate trades.
} 
purchasing type $p$ 's endowment at price $p$. Assuming that the monopsonist can break such ties in his favor, he earns a profit

$$
w(p) \equiv \int_{[\underline{\theta}, p]}[v(\theta)-p] d F(\theta) .
$$

In the Appendix, we show that the function $w: \mathbb{R} \rightarrow \mathbb{R}$ defined by (2) is rightcontinuous and of locally bounded variation. Moreover, under Assumption 1, $w$ is also upper semicontinuous. Hence, since $w$ vanishes over $(-\infty, \underline{\theta})$ and is strictly decreasing over $(\bar{\theta}, \infty), w$ attains its maximum at some point of $[\underline{\theta}, \bar{\theta}]$. To avoid ambiguities, define the monopsony price $p^{m}$ as the highest such point.

One may ask whether the monopsonist could further increase his profit by offering the seller a menu of contracts, allowing her to trade quantities in $(0,1)$, or, equivalently, by the revelation principle, a direct revelation mechanism $(Q, T):[\underline{\theta}, \bar{\theta}] \rightarrow[0,1] \times \mathbb{R}$ stipulating a quantity and a transfer as a function of the seller's report of her type. ${ }^{19}$ Samuelson (1984) and Myerson (1985) showed that, because of the linearity of preferences, the answer to this question is negative when $\mathbf{P}$ has a continuous and strictly positive density over $[\underline{\theta}, \bar{\theta}]$. The same logic applies to our more general setting.

LEMMA 1: The monopsonist cannot do better than offering to purchase the seller's whole endowment at price $p^{m}$.

\subsection{Aggregate Equilibrium Allocations}

In this section, we show that, generically, all equilibria of the nonexclusive competition game lead to essentially the same aggregate equilibrium outcome. To this end, define $p^{*}$ as the supremum of those $p$ such that $w(p)>0$, setting $p^{*}=\underline{\theta}$ if there are none. Intuitively, $p^{*}$ is the highest price at which the seller's endowment can be profitably bought. Since $w$ is right-continuous and upper semicontinuous, one necessarily has $w\left(p^{*}\right)=0$. Whenever $F\left(p^{*}\right)>0$, this equality, given (2), can be rewritten under the more familiar form

$$
p^{*}=\mathbf{E}\left[v(\theta) \mid \theta \leq p^{*}\right] .
$$

That is, $p^{*}$ is the expectation of the quality of the good, conditional on the seller being ready to trade at price $p^{*}$. Note that if $\mathbf{E}[v(\theta)]>\bar{\theta}$, so that $w(\bar{\theta})>$ 0 , then $p^{*}=\mathbf{E}[v(\theta)]$. A further implication of the right-continuity and upper semicontinuity of $w$ is that $p^{*}$ may be an atom of $\mathbf{P}$ only as long as $v\left(p^{*}\right)=p^{*}$. Therefore, in any case, if trade were to take place at price $p^{*}$, the way type $p^{*}$ would trade at that price would be irrelevant to the buyers' profits. To avoid discussing nongeneric cases, we make the following assumption.

\footnotetext{
${ }^{19}$ It follows from the linearity of preferences that the monopsonist cannot increase his profit by offering a stochastic mechanism.
} 
ASSUMPTION 2: If $p>p^{*}$, then $w(p)<0$.

A useful observation is that, under Assumption 2, one not only has $\mathbf{E}[v(\theta)] \leq$ $\bar{\theta}$ if and only if $p^{*} \leq \bar{\theta}$, but also $p^{*}=\bar{\theta}$ if and only if $\mathbf{E}[v(\theta)]=\bar{\theta}$. Moreover, if $F\left(p^{*}\right)>0, p^{*}$ is the unique equilibrium price in a game where buyers strategically set prices, but are restricted to bid for the seller's whole endowment; alternatively, $p^{*}$ is the highest equilibrium price in a competitive market in the spirit of Akerlof (1970), where sellers and buyers act as price takers and where each seller can deal with at most one buyer, to whom she can only sell her whole endowment (Mas-Colell, Whinston, and Green (1995, Chapter 13, Section B)). If one allows for arbitrary trades and nonexclusive competition, the following result holds.

PROPOSITION 1: In any equilibrium of the nonexclusive competition game, the aggregate equilibrium allocations satisfy

$$
(Q(\theta), T(\theta))= \begin{cases}\left(1, p^{*}\right), & \text { if } \underline{\theta} \leq \theta<p^{*}, \\ (0,0), & \text { if } \bar{\theta} \geq \theta>p^{*},\end{cases}
$$

and each buyer earns zero profit.

Therefore, with the exception of type $p^{*}$, whose behavior, as discussed above, is irrelevant to the buyers' profits, aggregate quantities and transfers are the same in any equilibrium of the nonexclusive competition game, and correspond to those that would obtain in the highest price competitive equilibrium of Akerlof's (1970) model: all the seller's types $\theta<p^{*}$ sell their whole endowment, while all the seller's types $\theta>p^{*}$ do not trade at all. Observe in particular that if $p^{*}=\underline{\theta}$ and $\underline{\theta}$ is not an atom of $\mathbf{P}$, trade occurs with probability zero in equilibrium and the market breaks down completely. At the other extreme, if $\mathbf{E}[v(\theta)] \geq \bar{\theta}$, competition among buyers bids up the price $p^{*}$ of the seller's endowment to its average value $\mathbf{E}[v(\theta)]$ for the buyers, a price at which all types in the support of $\mathbf{P}$ are ready to trade. In general, since $p^{*} \geq p^{m}$, there is at least as much trade under nonexclusive competition as in the monopsony case, which does not come as a surprise. Finally, it should be noted that although the equilibrium outcomes of our model are in line with Akerlof (1970), a distinctive feature of our approach is that buyers act strategically and compete through nonexclusive menus of contracts for the divisible good offered by the seller. Thus, Proposition 1 provides a novel game-theoretic foundation for Akerlof's (1970) predictions in a setting where, in addition to nonexclusivity, few restrictions on feasible trades or instruments are imposed.

The intuition for Proposition 1 can be easily understood in the context of a free-entry equilibrium. Suppose that $p^{*}>\underline{\theta}$ and that some type $\theta_{1} \in\left[\underline{\theta}, p^{*}\right)$ who is not an atom of $\mathbf{P}$ sells an aggregate quantity $Q\left(\theta_{1}\right)<1$ in equilibrium. Since incentive compatibility implies that the aggregate quantity traded by the 
seller must be a nonincreasing function of her type, it follows from the definition of $p^{*}$ that one can moreover choose $\theta_{1}$ so that $w\left(\theta_{1}\right)>0$. Suppose then that an entrant offers to buy a quantity $1-Q\left(\theta_{1}\right)$ at unit price $\theta_{1}$. Clearly, types $\theta>\theta_{1}$ will reject this new contract, because its unit price is too low from their viewpoint. By contrast, type $\theta_{1}$ is indifferent: she can accept the entrant's offer, which yields her no profit, and, as before, sell the remaining part $Q\left(\theta_{1}\right)$ of her endowment to the other buyers. Because types $\theta<\theta_{1}$ are even more eager to sell, they will all choose to sell their whole endowment, and therefore accept the entrant's offer. Overall, the entrant's profit would then be $\left[1-Q\left(\theta_{1}\right)\right] w\left(\theta_{1}\right)>0$, implying that entry would be profitable, a contradiction. Thus, aggregate trades must be constant and equal to 1 for types $\theta \in\left[\underline{\theta}, p^{*}\right)$. As for types $\theta \in\left(p^{*}, \bar{\theta}\right]$, it follows from the definition of $p^{*}$ that even a monopsonist would be unable to extract profits from them. This implies that they must be completely excluded from trade in equilibrium.

The actual proof of Proposition 1 is more delicate. For any buyer $i$, let $\left(q^{i}(\theta), t^{i}(\theta)\right)$ be the contract traded by type $\theta$ with buyer $i$. In line with the above free-entry argument, the key idea is that any buyer $i$ can pivot on the trades offered by his competitors: this essentially amounts to offering a contract $\left(q^{i}\left(\theta_{1}\right)+1-Q\left(\theta_{1}\right), t^{i}\left(\theta_{1}\right)+\theta_{1}\left[1-Q\left(\theta_{1}\right)\right]\right)$, which types $\theta<\theta_{1}$ will trade along with the contracts $\left(q^{j}\left(\theta_{1}\right), t^{j}\left(\theta_{1}\right)\right), j \neq i$, thereby selling the remaining part of their endowment to the buyers other than $i$. However, one problem faced by any such buyer $i$, as opposed to an entrant, is that he needs to make sure that the choices made by types $\theta>\theta_{1}$ in the menu he offers remain close to their equilibrium choices, so that the profits he earns by trading with them do not vary too much compared to equilibrium. In particular, buyer $i$ must avoid negative sorting of these types following his deviation, which could occur if he merely added the contract $\left(q^{i}\left(\theta_{1}\right)+1-Q\left(\theta_{1}\right), t^{i}\left(\theta_{1}\right)+\theta_{1}\left[1-Q\left(\theta_{1}\right)\right]\right)$ to his equilibrium menu: indeed, some types $\theta>\theta_{1}$ could be indifferent between various contracts in buyer $i$ 's equilibrium menu and could, therefore, punish him following his deviation by selecting contracts that would be less favorable from his point of view. In the proof of Proposition 1, we show how buyer $i$ can circumvent this difficulty by offering contracts targeted at types $\theta>\theta_{1}$ that are both close to their equilibrium choices and such that each of these types has a unique best response given the menus offered by the other buyers. This restores a form of strict incentive compatibility without having recourse to any equilibrium refinement concept. Finally, we show that if some type $\theta_{1} \in\left[\underline{\theta}, p^{*}\right)$ who is not an atom of $\mathbf{P}$ sells an aggregate quantity $Q\left(\theta_{1}\right)<1$ in equilibrium, then a deviation such as that outlined above is profitable to at least one buyer.

\subsection{Equilibrium Existence}

We now establish that the nonexclusive competition game always has an equilibrium. More precisely, we show that there always exists an equilibrium 
in which all buyers post linear price schedules. In this equilibrium, any quantity can be traded at a unit price equal to the expected quality of the good, conditional on trade taking place.

PROPOSITION 2: The nonexclusive competition game always has an equilibrium in which each buyer offers the menu

$$
\left\{(q, t) \in[0,1] \times \mathbb{R}_{+}: t=p^{*} q\right\}
$$

and thus stands ready to purchase any quantity of the good at the constant unit price $p^{*}$.

The intuition for this result is as follows. Suppose that $p^{*}>\underline{\theta}$ and that some buyer attempts to deviate from the proposed menu. A contract $(q, t)$ such that $t<p^{*} q$ will not be traded by any type, given that she can always trade the quantity $q$ at price $p^{*} q$ with the nondeviating buyers. Thus, the deviating buyer's menu is attractive only if it contains a contract $(q, t)$ such that $t \geq p^{*} q$. Since the seller has the option to trade any fraction of her endowment at unit price $p^{*}$ with the nondeviating buyers, we can assume that all types $\theta \leq p^{*}$ select the same contract $(q, \underline{t})$ from the deviating buyer's menu and then sell the remaining part $1-q$ of their endowment at price $p^{*}(1-q)$. Thus, the profit that the deviating buyer earns by trading with these types is $F\left(p^{*}\right)\left\{\mathbf{E}\left[v(\theta) \mid \theta \leq p^{*}\right] q-\underline{t}\right\}$, which is at most zero since $\mathbf{E}\left[v(\theta) \mid \theta \leq p^{*}\right]=p^{*}$ by (3) and since $t \geq p^{*} q$ by the above reasoning. Thus, given the postulated continuation equilibrium, no buyer can deviate and make profits with types $\theta \leq p^{*}$. As for types $\theta>p^{*}$, we already observed that even a monopsonist would be unable to extract profits from them. This is a fortiori true for a deviating buyer, which shows that no deviation from the candidate equilibrium can be profitable.

REMARK: Applications of common agency games with incomplete information often impose restrictions on the menus offered by the principals that guarantee that each agent's type has a unique best response (see Martimort and Stole (2009) for a discussion of this point). When a notion of equilibrium refinement is introduced, attention is typically restricted to strongly robust equilibria (Peters (2001)). An equilibrium of a common agency game is strongly robust if the agent's choice is optimal from the viewpoint of each principal, both on the equilibrium path and following a unilateral deviation by this principal. In our nonexclusive competition game, this is demanding too much. Indeed, since an equilibrium typically involves that different types of the seller pool and trade their whole endowment, each buyer could always gain if the contracts he offers were only traded by those types of the seller with whom he makes profits. Such positive sorting, however, is clearly inconsistent with equilibrium. Related to this, in the equilibrium described in Proposition 2, the 
strategy of the seller is constructed in such a way that if a buyer deviates, all types $\theta \leq p^{*}$ pool and trade the same contract with him; such a behavior in the continuation subgame is sufficient to deter deviations.

It should be noted that the proof of Proposition 2 does not rely on Assumption 2. In light of Proposition 1, what this assumption ensures is that $p^{*}$ is the unique unit price consistent with a linear price schedule equilibrium. When it fails to hold, there may be nongeneric situations in which multiple linear price schedule equilibria coexist. This is, for instance, the case when the support of $\mathbf{P}$ consists of two points $\underline{\theta}$ and $\bar{\theta}$ such that $\underline{\theta}<v(\underline{\theta})<\bar{\theta}$ and $\mathbf{E}[v(\theta)]=\bar{\theta}$. Then $p^{*}=v(\underline{\theta})$, and yet $w(\bar{\theta})=0$, in contradiction with Assumption 2. In this case, it is easy to check that there exist two linear price schedule equilibria: a separating equilibrium with unit price $v(\underline{\theta})$, in which only type $\underline{\theta}$ actively trades, and a pooling equilibrium with unit price $\mathbf{E}[v(\theta)]$, in which both types $\underline{\theta}$ and $\bar{\theta}$ actively trade.

\subsection{Equilibrium Menus}

While the nonexclusive competition game always has a linear price schedule equilibrium, the aggregate equilibrium allocations can be supported by different menu offers. ${ }^{20}$ Yet, as we now show, equilibrium imposes significant restrictions on the structure of buyers' menus. We first characterize the equilibrium price of issued and traded contracts.

PROPOSITION 3: In any equilibrium of the nonexclusive competition game, the unit price of any issued contract is at most $p^{*}$ and the unit price of any traded contract is $p^{*}$.

This result illustrates how competition disciplines the buyers in our model: even though they are allowed to propose arbitrary menus of contracts, they end up trading at the same price in equilibrium. Moreover, even nontraded contracts must be issued at a unit price at most equal to $p^{*}$. If $p^{*}$ belongs to the support of $\mathbf{P}$, the proof is straightforward. Indeed, suppose that a contract with unit price above $p^{*}$ were issued. Then, since type $p^{*}$ earns zero profit in equilibrium, she would actually have a strict incentive to trade this contract instead of those that she trades in equilibrium, and so would all types in a neighborhood of $p^{*}$; each of these types would thereby earn more than her equilibrium profit, a contradiction. If $p^{*}$ does not belong to the support of $\mathbf{P}$, the proof shows that one of the buyers could strategically use such a contract and pivot on it so as to increase his profit.

\footnotetext{
${ }^{20}$ See Attar, Mariotti, and Salanié (2009, Proposition 6) for how to construct equilibria in nonlinear price schedules in a two-type specification of the model.
} 
We now investigate which contracts need to be issued so as to support the aggregate equilibrium allocations. From a strategic viewpoint, what matters for each buyer is the outside option of the seller; for each buyer $i$ and for each menu profile $\left(C^{1}, \ldots, C^{n}\right)$, this is described by the set of aggregate allocations that remain available if buyer $i$ withdraws his menu offer $C^{i}$. One first has the following result.

PROPOSITION 4: If $p^{*}>\underline{\theta}$, then in any equilibrium of the nonexclusive competition game, the aggregate allocation $\left(1, p^{*}\right)$ remains available if any buyer withdraws his menu offer.

The unique aggregate equilibrium allocation must therefore remain available even if a buyer deviates from his equilibrium menu offer. When $\mathbf{E}[v(\theta)]>$ $\bar{\theta}$, so that $p^{*}=\mathbf{E}[v(\theta)]$, the reason is that this buyer may otherwise profitably attract the seller by offering to buy her endowment at a price slightly below $\mathbf{E}[v(\theta)]$. The proof is more involved when $\mathbf{E}[v(\theta)] \leq \bar{\theta}$, that is, $p^{*} \leq \bar{\theta}$. We show that if the allocation $\left(1, p^{*}\right)$ did not remain available if a buyer were to remove his equilibrium offer, then, for $\varepsilon>0$ close enough to zero, this buyer could pivot on the aggregate allocation that type $p^{*}-\varepsilon<p^{*}$ would optimally trade with the other buyers, and could secure a strictly positive profit by trading with types $\theta<p^{*}-\varepsilon$. The key insight of Proposition 4 is that no buyer is essential in providing the seller with her aggregate equilibrium allocation or her equilibrium profit. As an illustration, when there are two buyers, there is no equilibrium in which each buyer would only offer to purchase half of the seller's endowment. This rules out Cournot-like outcomes in which the buyers would simply share the market and in which all issued contracts would be actively traded by some type of the seller, as in Biais, Martimort, and Rochet (2000).

Equilibrium actually imposes much tighter restrictions on menus than those described in Propositions 3 and 4. Indeed, suppose, for instance, that $\underline{\theta}<p^{*}<$ $\bar{\theta}$ and that $\mathbf{P}$ is nonatomic and has full support over $[\underline{\theta}, \bar{\theta}]$. In line with standard adverse selection models, suppose further that $v(\theta)$ is strictly increasing and continuous in $\theta$. We argue that, in this case, there is no equilibrium in which each buyer only offers to trade the aggregate equilibrium allocation $\left(1, p^{*}\right)$. Indeed, any buyer could otherwise deviate by offering to purchase a quantity $1-\delta$ at price $p^{*}-\left(p^{*}-\varepsilon\right) \delta$ for some small and strictly positive numbers $\delta$ and $\varepsilon$. By construction, this is a cream-skimming deviation that is strictly appealing to types in $\left(p^{*}-\varepsilon, p^{*}+\varepsilon \delta /(1-\delta)\right)$ only. The deviating buyer would then earn a profit

$$
\int_{\left[p^{*}-\varepsilon, p^{*}+\varepsilon \delta /(1-\delta)\right]}\left[v(\theta)(1-\delta)-p^{*}+\delta\left(p^{*}-\varepsilon\right)\right] d F(\theta) .
$$

Since $p^{*}>\underline{\theta}$, and since $w\left(p^{*}\right)=0$ and $v$ is strictly increasing, one must have $v\left(p^{*}\right)>p^{*}$ by (3). Moreover, because $\underline{\theta}<p^{*}<\bar{\theta}$ and $\mathbf{P}$ has full support over 
$[\underline{\theta}, \bar{\theta}], \mathbf{P}$ puts strictly positive mass over any neighborhood of $p^{*}$. Since $v$ is continuous, it follows that the deviating buyer's profit (4) is strictly positive for $\delta$ and $\varepsilon$ close enough to zero, a contradiction. To block such deviations, contracts must be issued that are not necessarily traded in equilibrium, but which the seller has an incentive to trade if a buyer attempts to deviate. To play this deterrence role, the corresponding allocations must remain available if any buyer withdraws his menu offer. For instance, the above cream-skimming deviation is blocked if the quantity $\delta$ can always be sold at unit price $p^{*}$, for then all types $\theta \in\left[\underline{\theta}, p^{*}+\varepsilon \delta /(1-\delta)\right)$ have the same incentives to trade the deviating buyer's contract, resulting in a strictly negative profit for the deviating buyer. This, in essence, is the logic underlying the linear price schedule equilibrium described in Proposition 2. In this equilibrium, the number of contracts available off the equilibrium path is large, since the menus offered by the buyers are infinite collections of contracts. The following result generalizes this insight, reflecting that in equilibrium infinitely many cream-skimming deviations need to be blocked.

PROPOSITION 5: If $p^{*}>\underline{\theta}$ and there exists some $\theta_{0} \in\left(\underline{\theta}, p^{*}\right)$ such that

$$
\int_{\left[\theta_{0}, p^{*}\right]}\left[v(\theta)-p^{*}\right] d F(\theta)>0
$$

then in any equilibrium of the nonexclusive competition game, any quantity close enough to zero remains available for trade if any buyer withdraws his menu offer.

Because $\int_{\left[\underline{\theta}, p^{*}\right]}\left[v(\theta)-p^{*}\right] d F(\theta)=w\left(p^{*}\right)=0$, condition (5) holds for instance when $v(\theta)$ is strictly increasing in $\theta$, and there are at least two types in the support of $\mathbf{P}$ who differ from $p^{*}$ and who actively trade in equilibrium.

REMARK: What if the only type in the support of $\mathbf{P}$ who differs from $p^{*}$ and who actively trades in equilibrium is type $\underline{\theta}$, as in the two-type model of Section 3 when $\mathbf{E}[v(\theta)]<\bar{\theta}$ ? Then, because $w\left(p^{*}\right)=0$ and $v\left(p^{*}\right)=p^{*}$ if $p^{*}$ is an atom of $\mathbf{P}$, one must have $p^{*}=v(\underline{\theta})$. In the Appendix, we show that if there exists $\tilde{p}>p^{*}$ such that

$$
\int_{\left[p^{*}, \tilde{p}\right]}[v(\theta)-\tilde{p}] d F(\theta)>0,
$$

then in any equilibrium of the nonexclusive competition game, infinitely many allocations remain available if any buyer withdraws his menu offer. ${ }^{21}$ Condition (6) is easily verified when the support of $\mathbf{P}$ consists of two types $\underline{\theta}$ and $\bar{\theta}$ such

\footnotetext{
${ }^{21}$ In contrast with Proposition 5, this only shows the necessity of a countably infinite number of contracts.
} 
that $\underline{\theta}<v(\underline{\theta})$ and $\mathbf{E}[v(\theta)]<\bar{\theta}<v(\bar{\theta})$; it is also satisfied when $\underline{\theta}<v(\underline{\theta})$ and the gains from trade $v(\theta)-\theta$ are strictly increasing in the seller's type $\theta$.

A key implication of these results is that even when the seller's type space is finite, equilibrium menus should typically display an infinite number of latent contracts, the role of which is only to deter deviations by the buyers. In light of the delegation principle for common agency games (Peters (2001), Martimort and Stole (2002)), this suggests that a rich communication structure implicitly lies behind our Akerlof-like equilibrium outcomes: in a game where buyers would compete through arbitrary indirect mechanisms, subject to nonexclusivity, an infinite number of messages should be available to the seller, allowing her to communicate to each buyer information on deviations by the other buyers. Note by contrast that with a finite number of types, the corresponding equilibrium allocations could not be supported if buyers were restricted to compete through simple direct mechanisms that only ask the seller to communicate her type. The possibility to support equilibrium allocations in a game relative to an arbitrary set of indirect mechanisms, but not in the corresponding direct mechanism game, has been acknowledged as a failure of the revelation principle in common agency games and so far has been documented in purely abstract game-theoretic examples. ${ }^{22}$ A contribution of our analysis is to exhibit a natural and relevant economic setting that exhibits this feature.

It should be emphasized that standard arguments against the use of latent contracts do not apply in our setting. For instance, latent contracts are often criticized for allowing one to support multiple equilibrium allocations and even for inducing an indeterminacy of equilibrium. ${ }^{23}$ This is not the case in our model, since aggregate equilibrium allocations are generically unique. Another common criticism is that some equilibrium allocations can only be sustained by latent contracts that would make losses off the equilibrium path in the hypothetical case where they would be traded. ${ }^{24}$ Again, this need not be the case in our model. For instance, following a buyer's deviation in the equilibrium constructed in Proposition 2, all types $\theta \leq p^{*}$ select the same contract $(\underline{q}, \underline{t})$ from the deviating buyer's menu and then sell the remaining part $1-\underline{q}$ of their endowment at price $p^{*}(1-\underline{q})$ to the nondeviating buyers. These types may in particular trade with a single nondeviating buyer, who, according to (3), would not make losses off the equilibrium path. One can actually construct examples of equilibria sustained by latent contracts that would be strictly profitable to their issuers if any type were to trade them. ${ }^{25}$

\footnotetext{
${ }^{22}$ See, for instance, Peck (1997), Peters (2001), and Martimort and Stole (2002).

${ }^{23}$ In a complete information setting, Martimort and Stole (2003) showed that latent contracts can be used to support any level of trade between the perfectly competitive outcome and the Cournot outcome.

${ }^{24}$ Attar and Chassagnon (2009) provided an example of a moral hazard insurance economy in which latent contracts with negative virtual profits are a necessary feature of equilibrium.

${ }^{25}$ See Attar, Mariotti, and Salanié (2009, Proposition 6(ii)).
} 


\section{ROBUSTNESS}

In this section, we discuss the robustness of our results. We first examine the case where the buyers do not face a single seller, but several of them. We then compare our results with those obtained by Biais, Martimort, and Rochet (2000) in a model of nonexclusive competition under adverse selection where the seller has strictly convex preferences.

\subsection{Trading With Multiple Sellers}

Suppose now that the buyers $i=1, \ldots, n$ face a finite number of sellers indexed by $j=1, \ldots, l$, where $l \geq 2$. Each seller is endowed with one unit of a perfectly divisible good. Let $q_{j}^{i}$ be the quantity of the good purchased by buyer $i$ from seller $j$, and let $t_{j}^{i}$ be the transfer he makes in return. Feasible trades $\left(\left(q_{1}^{1}, t_{1}^{1}\right), \ldots,\left(q_{1}^{n}, t_{1}^{n}\right), \ldots,\left(q_{l}^{1}, t_{l}^{1}\right), \ldots,\left(q_{l}^{n}, t_{l}^{n}\right)\right)$ are such that $q_{j}^{i} \geq 0$ for all $i$ and $j$, and $\sum_{i} q_{j}^{i} \leq 1$ for all $j$. Seller $j$ 's profit from trading $\left(Q_{j}, T_{j}\right)=\left(\sum_{i} q_{j}^{i}, \sum_{i} t_{j}^{i}\right)$ in the aggregate is

$$
T_{j}-\theta_{j} Q_{j}
$$

where $\theta_{j}$ is seller $j$ 's opportunity cost of giving away her endowment. Buyer $i$ 's profit from trading $\left(\sum_{j} q_{j}^{i}, \sum_{j} t_{j}^{i}\right)$ is

$$
\sum_{j}\left[v\left(\theta_{j}\right) q_{j}^{i}-t_{j}^{i}\right] .
$$

Each seller is privately informed of her opportunity cost. For expositional simplicity, and unless stated otherwise, we assume that each seller's type has marginal distribution P. We also maintain Assumptions 1 and 2.

\section{Bilateral Private Contracting}

Because the agents' profit functions are separable, it is natural to start with a decentralized trading structure in which each buyer $i$ proposes a menu of contracts $C_{j}^{i}$ to each seller $j$, who then makes her trading decisions without observing the menus offered to the other sellers. That is, contracting is bilateral and private. In practice, this is a key feature of important financial markets, such as limit order markets (Parlour and Seppi (2008)) or over-the-counter markets (Brunnermeier (2009)). Bilateral contracting in multiple-principal multipleagent games has been studied under complete information by Prat and Rustichini (2003). Our setting is different from theirs in that there are no externalities across principals (buyers) and that there is incomplete information about the agents' (sellers) types. Moreover, Prat and Rustichini (2003) restricted principals to make simple take-it-or-leave-it offers, while we allow buyers to 
offer arbitrary menus of contracts. ${ }^{26}$ The following result shows the robustness of our equilibrium characterization in a multiple-buyer multiple-seller environment with bilateral and private contracting.

LEMMA 2: In any equilibrium of the multiple-buyer multiple-seller nonexclusive competition game with bilateral private contracting, each seller's type different from $p^{*}$ trades the same aggregate quantities and transfers as in any equilibrium of the multiple-buyer single-seller nonexclusive competition game.

This result easily extends to the case of heterogenous sellers, provided the corresponding functions $v_{j}$ and distributions $\mathbf{P}_{j}$ satisfy Assumptions 1 and 2.

\section{Multilateral Public Contracting}

The restriction to bilateral private contracting plays a key role in Lemma 2. If multilateral public contracting is allowed instead, a very large number of allocations can be supported in equilibrium by properly selecting the continuation equilibria in the subgames played by the sellers following any buyer's unilateral deviation. Indeed, following this logic, Peters and Troncoso Valverde (2010) and Yamashita (2010) established folk theorems for a large class of multipleprincipal multiple-agent games, which includes the current setting.

Using the mechanisms introduced by Yamashita (2010), the equilibrium allocations of the multiple-buyer multiple-seller nonexclusive competition game with multilateral public contracting can be characterized as follows. ${ }^{27}$ Each buyer asks the sellers to report their types and to vote for an incentive compatible allocation rule, which assigns an aggregate trade to each profile of reports by the sellers. An allocation rule is selected if it receives the majority of the sellers' votes. Since the vote of each single seller is irrelevant if all the other sellers vote for the same allocation rule, for each incentive compatible allocation rule there is an equilibrium where each seller votes for it and truthfully reports her type. If a buyer deviates toward a different mechanism, sellers can punish him by selecting an allocation rule that provides him with his minmaxmin value, that is, with the maximal profit he earns when his competitors select mechanisms that cause him the greatest harm and sellers coordinate on

\footnotetext{
${ }^{26}$ Under bilateral contracting, one could consider more general communication mechanisms by which each principal would assign a contract to each agent, conditional on the message that this agent would send him, but not on the other agents' messages. In fact, Han (2006, Theorem 1) established that as long as one restricts attention to pure strategy perfect Bayesian equilibria, any profile of equilibrium payoffs that is supported by such bilateral communication mechanisms can also be supported by letting each principal independently offer a menu of contracts to each agent. This result holds both in the situation where all agents publicly observe all offered mechanisms and in the situation where each agent only observes the mechanisms that are offered to her.

${ }^{27}$ Note that Yamashita's (2010) results are obtained under the additional restriction $l \geq 3$.
} 
the worst continuation equilibrium from his point of view. ${ }^{28}$ In our setting, one can show that, for each buyer $i$, this minmaxmin value $\underline{v}^{i}$ can be attained and is actually equal to zero. Indeed, one has $\underline{v}^{i} \geq 0$, because buyer $i$ always has the option not to trade. In addition, one also has $\underline{v}^{i} \leq 0$, since no buyer can make profits when his competitors stand ready to buy any quantity from each of the buyers at the constant unit price $p^{*}$, in line with the linear price schedule equilibrium described in Proposition 2. One can then show along the lines of Yamashita (2010, Theorem 1) that any incentive compatible allocation in which each buyer's profit is at least zero can be supported in equilibrium.

To provide a simple illustration of this result, suppose that each buyer commits to a mechanism by which he offers to buy any quantity from each of the sellers at a constant unit price equal to the monopoly price $p^{m}$, unless at least $l-1$ sellers send him some message $\neg m$. In this last contingency, he offers to buy any quantity from each of the sellers at a constant unit price equal to the competitive price $p^{*}$. It is straightforward to check that the monopoly price $p^{m}$ can be supported in equilibrium by having sellers send the message $\neg m$ to each nondeviating buyer in the subgame following any buyer's unilateral deviation. A similar reasoning guarantees that every price between $p^{*}$ and $p^{m}$ can be supported in equilibrium if multilateral public contracting is allowed. ${ }^{29}$

\subsection{Comparison With Biais, Martimort, and Rochet (2000)}

In an influential paper, Biais, Martimort, and Rochet (2000) studied a model of nonexclusive competition under adverse selection where the utility a type $\theta$ seller derives from trading $(Q, T)$ in the aggregate is

$$
T-\theta Q-\frac{\alpha}{2} Q^{2}
$$

for some fixed parameter $\alpha>0$. One might be tempted to interpret our model as a limit case of theirs when $\alpha$ goes to zero. Yet this would overlook the fact that aggregate trades in our model are subject to the capacity constraint $Q \leq 1$, while aggregate trades in their model are unrestricted, leading to strikingly different results.

\section{Pooling and Capacity Constraints}

Recall first that, in the present paper, all types of the seller who trade in equilibrium sell their endowment at the same price and are, therefore, pooled on the same aggregate allocation. By contrast, in the equilibrium characterized

\footnotetext{
${ }^{28}$ See Yamashita (2010) for a precise definition. Observe that because there are no externalities across sellers, the set of pure strategy continuation equilibria is nonempty for any profile of mechanisms, as required by Yamashita's (2010) definition.

${ }^{29}$ The equilibrium mechanisms proposed in this example can easily be reformulated as recommendation mechanisms like those considered in Yamashita (2010).
} 
by Biais, Martimort, and Rochet (2000), all active types are separated and end up trading different aggregate allocations. This of course reflects the fact that both the buyers' menus and the seller's preferences are taken to be strictly convex in their analysis. We now argue that the presence of a capacity constraint is another reason why our findings differ from theirs.

To emphasize this point, let us consider a model of nonexclusive competition where the seller can be of two types, with preferences that are strictly convex and satisfy a strict single-crossing condition, but are otherwise arbitrary. These preferences encompass those considered by Biais, Martimort, and Rochet (2000); they may also be used to approximate those considered in the present paper. ${ }^{30}$ We showed in Attar, Mariotti, and Salanié (2010, Proposition 4) that when there is no capacity constraint, there exists no pooling equilibrium in which both types of the seller end up trading a strictly positive quantity. This is because any active buyer could gain from trading a different contract with each type of the seller, in such a way as to increase the aggregate trades of the type with the lowest opportunity cost to sell, who offers a good of relatively lower quality. Hence, one cannot approximate the pooling outcome that may arise in our model as a limit of equilibrium outcomes in a sequence of games where trades are unrestricted.

By contrast, when a capacity constraint is introduced, additional trades may no longer be feasible and pooling equilibria may be supported. In this respect, it is interesting to observe that the characterization results derived for the two-type example of Section 3 can be extended to situations where the seller has strictly convex preferences, as long as her capacity constraint is effectively binding. Specifically, suppose that type $\theta$ 's preferences over aggregate trades $(Q, T)$ are represented by $u(\theta, Q, T)$, which is assumed to be continuously differentiable and strictly quasiconcave in $(Q, T)$, and let $\tau(\theta, Q, T)$ be the corresponding marginal rate of substitution of the good for transfers at $(Q, T)$. Here $\theta$ can take two values $\underline{\theta}$ and $\bar{\theta}$, such that $v(\bar{\theta})>v(\underline{\theta})$ and $\tau(\bar{\theta}, Q, T)>\tau(\underline{\theta}, Q, T)$ : type $\bar{\theta}$ provides a more valuable good to the buyers than type $\underline{\theta}$, but at a higher opportunity cost. Consider then a candidate equilibrium in linear price schedules. One can show that a pooling equilibrium obtains whenever $\tau(\bar{\theta}, 1, \mathbf{E}[v(\theta)])<\mathbf{E}[v(\theta)]$, while a separating equilibrium obtains whenever $\tau(\bar{\theta}, 0,0)>\mathbf{E}[v(\theta)]>v(\underline{\theta})>\tau(\underline{\theta}, 0,0)$. Observe that these conditions generalize those we used in Section 3 to characterize mild and strong adverse selection.

\footnotetext{
${ }^{30}$ For instance, the preferences of a type $\theta$ seller over aggregate trades could be represented by the utility function $(Q, T) \mapsto T-\theta Q-\alpha Q^{p} / p$ for some fixed parameters $\alpha>0$ and $p>1$. Biais, Martimort, and Rochet's (2000) specification corresponds to $p=2$. As $p$ goes to $\infty$, this utility function converges uniformly to $(Q, T) \mapsto T-\theta Q$ over $[0,1] \times \mathbb{R}$, while involving for any $Q>1$ a penalty for the seller that grows without bounds. As the discussion below suggests, however, there is a sense in which this approximation of our setting is misleading, because it only mimics, at the level of preferences, the presence of a capacity constraint, which has rather to do with the trading technology.
} 


\section{Zero Profit?}

A key feature of our analysis is that buyers just break even in all equilibria. This stands in sharp contrast to the equilibrium characterized by Biais, Martimort, and Rochet (2000), in which buyers earn strictly positive profits. However, it should be noted that this equilibrium is derived under the assumption that there is a continuum of seller's types. By contrast, in the two-type case, Attar, Mariotti, and Salanié (2010) showed that buyers must earn zero profit in any equilibrium; this result notably applies to the situation where the seller's utility function is as specified in Biais, Martimort, and Rochet (2000). One is therefore led to the conclusion that if the seller has strictly convex preferences and trades are unrestricted, the properties of equilibria crucially depend on the cardinality of the set of seller's types. This suggests, in any case, that further work is needed to understand nonexclusive competition in such environments. Observe, by contrast, that this difficulty does not arise in the present paper, since our results are valid for any type distribution, whether discrete, continuous, or mixed, as long as it satisfies Assumptions 1 and 2.

\section{CONCLUSION}

In this paper, we studied a model of trade under adverse selection in which buyers compete for a good, the quality of which is privately observed by the seller who offers it. Two distinctive features of our model are that the good is divisible, and that competition between buyers is nonexclusive. This means that the seller may choose to trade with several of them, and, crucially, that contracting between the seller and each buyer is bilateral, so that buyers cannot monitor each others' trades with the seller. Besides this, we impose few restrictions on instruments: buyers can offer arbitrary menus of contracts or, equivalently, price schedules. In this setting, we show that equilibria exist under mild conditions, unlike in standard models of exclusive competition under adverse selection in the spirit of Rothschild and Stiglitz (1976). Aggregate equilibrium allocations are generically unique and correspond to the highest price competitive equilibrium in Akerlof (1970). Linear price schedule equilibria exist in which buyers stand ready to purchase any quantity at this constant unit price. These results hold regardless of the number of buyers, even though buyers act strategically. In addition, a large number of contracts is shown to be necessary to support the equilibrium allocations, although only a small fraction of them may end up being traded in equilibrium. The wide applicability of our assumptions, along with the simplicity of the equilibrium predictions, suggest that our model could easily be used as a building block in applications, for instance, in finance or macroeconomics.

Our work may also be useful for studies of markets prone to adverse selection, because the Akerlof-like outcomes we emphasize are a simple alternative to the Rothschild and Stiglitz-like outcomes that are usually considered in the applied literature. Take for instance the question of testing for the presence 
of adverse selection on insurance markets. ${ }^{31}$ Most of the literature relies on the idea that riskier agents should choose higher coverage, and thus that one should observe a positive correlation between risk and coverage. It is fair to say that, so far, empirical tests of this prediction have led to mixed results. ${ }^{32}$ Notice, however, that some of these empirical studies focus on markets in which competition is nonexclusive, such as life insurance (Cawley and Philipson (1999)) or annuity markets (Finkelstein and Poterba $(2002,2004)$ ). This leads to the following remarks. First, the positive correlation property stated above is valid only insofar as one can observe the total coverage chosen by each agent. While this is a relatively easy task under exclusive competition, under nonexclusive competition, this would require surveys of consumer finances, not merely samples of policies or data emanating from a single insurance company. Next, our results show that agents who buy some insurance end up with the same level of coverage and, therefore, that the positive correlation property no longer holds under nonexclusive competition. Indeed, Finkelstein and Poterba $(2002,2004)$ found evidence of adverse selection when comparing insured agents to noninsured agents or when comparing agents who choose backloaded annuities to agents with flatter annuity profiles. However, the evidence is much weaker when it comes to comparing agents with different levels of coverage-a negative finding they share with Cawley and Philipson (1999) and that is in line with our theoretical results. Finally, another prediction of standard exclusive competition models is that coverage should be priced at an increasing rate. The above cited studies empirically reject this feature, instead documenting linear pricing of coverage, with some bulk discounts apparently arising from administrative costs. Once more, this finding is consistent with our results. At any rate, these remarks suggest that more sophisticated procedures need to be designed to test for the presence of adverse selection in markets where competition is nonexclusive.

\section{APPENDIX}

PROOF OF LEMMA 1: Lemma 1 is a direct consequence of a slightly stronger result, which we now state for future reference. Consider the following constrained monopsony problem, parameterized by $\left(\theta_{0}, \theta_{1}, Q_{0}, Q_{1}\right)$, where $\underline{\theta} \leq$ $\theta_{0}<\theta_{1}<\infty$ and $0 \leq Q_{1}<Q_{0} \leq 1$ :

$$
\max \left\{\int_{\left[\underline{\left.\underline{\theta}, \theta_{1}\right]}\right.}[v(\theta) Q(\theta)-T(\theta)] d F(\theta)\right\}
$$

\footnotetext{
${ }^{31}$ See Chiappori and Salanié (2003) and Cohen and Siegelman (2010) for surveys of that literature.

${ }^{32}$ See, for instance, Chiappori and Salanié (2000). Chiappori, Jullien, Salanié, and Salanié (2006) proposed an explanation based on differences in profits between contracts. Cohen and Siegelman (2010) discussed other possible explanations.
} 
subject to the incentive compatibility and individual rationality constraints

$$
T(\theta)-\theta Q(\theta) \geq \begin{cases}T\left(\theta^{\prime}\right)-\theta Q\left(\theta^{\prime}\right) & \forall\left(\theta, \theta^{\prime}\right) \in\left[\underline{\theta}, \theta_{1}\right]^{2}, \\ 0 & \forall \theta \in\left[\underline{\theta}, \theta_{1}\right],\end{cases}
$$

and to two additional constraints on quantities

$$
Q(\theta) \begin{cases}=Q_{0} & \forall \theta \in\left[\underline{\theta}, \theta_{0}\right), \\ \geq Q_{1} & \forall \theta \in\left[\theta_{0}, \theta_{1}\right] .\end{cases}
$$

The clause (10) is empty if $\theta_{0}=\underline{\theta}$; in this case, we must treat $Q(\underline{\theta})$ as an additional control variable taking its values in $\left[Q_{1}, 1\right]$, while $Q_{0}$ is irrelevant. We show below that the value of problem (7)-(11) is

$$
Q_{1} w\left(\theta_{1}\right)+\left[1_{\left\{\theta_{0}=\underline{\theta}\right\}}\left(1-Q_{1}\right)+1_{\left\{\theta_{0}>\theta\right\}}\left(Q_{0}-Q_{1}\right)\right] \max _{\theta \in\left[\theta_{0}, \theta_{1}\right]}\{w(\theta)\} .
$$

Since the unconstrained monopsony problem corresponds to $\left(\theta_{0}, \theta_{1}, Q_{0}, Q_{1}\right)=$ $(\underline{\theta}, \bar{\theta}, 1,0)$, it follows from (12) and the definition of $p^{m}$ that the maximum profit that the unconstrained monopsonist can earn is $w\left(p^{m}\right)$.

To derive (12), we repeatedly use the following integration by parts formula for functions of locally bounded variation (Dellacherie and Meyer (1982, Chapter VI, Theorem 90)).

FACT 1: Let $a:[\underline{\theta}, \infty) \rightarrow \mathbb{R}$ and $b:[\underline{\theta}, \infty) \rightarrow \mathbb{R}$ be two right-continuous functions of locally bounded variation, and set $a(\underline{\theta}-) \equiv 0$ and $b(\underline{\theta}-) \equiv 0$ by convention. Then the function $a b$ is of locally bounded variation and

$$
a(\theta) b(\theta)=\int_{[\underline{\theta}, \theta]}[a(\vartheta) d b(\vartheta)+b(\vartheta-) d a(\vartheta)]
$$

for all $\theta \in[\underline{\theta}, \infty)$.

The proof of Lemma 1 then goes through a series of steps.

Step 1. We first check that $w$ is right-continuous, of locally bounded variation, and upper semicontinuous. For all $(p, \varepsilon) \in \mathbb{R} \times \mathbb{R}_{+}$, we have by (2) that

$$
|w(p+\varepsilon)-w(p)| \leq \int_{(p, p+\varepsilon] \cap[\underline{\theta}, \bar{\theta}]}|v(\theta)-p| d F(\theta)+\varepsilon F(p+\varepsilon),
$$

which goes to zero as $\varepsilon$ goes to zero because $v$ is bounded over the support of $\mathbf{P}$ and $F$ is right-continuous. Hence, $w$ is right-continuous at any $p \in \mathbb{R}$. Next, 
for each subdivision $\underline{\theta}=p_{0}<p_{1}<\cdots<p_{k}=\bar{\theta}$ of $[\underline{\theta}, \bar{\theta}]$, we have by (2) that

$$
\begin{aligned}
& \sum_{i=1}^{k}\left|w\left(p_{i}\right)-w\left(p_{i-1}\right)\right| \\
& \quad \leq \sum_{i=1}^{k}\left|\int_{\left(p_{i-1}, p_{i}\right]} v(\theta) d F(\theta)-p_{i} F\left(p_{i}\right)+p_{i-1} F\left(p_{i-1}\right)\right| \\
& \quad \leq \int_{(\underline{\theta}, \bar{\theta}]}|v(\theta)| d F(\theta)+\bar{\theta}-\underline{\theta} F(\underline{\theta}),
\end{aligned}
$$

so that $w$ is of bounded variation over $[\underline{\theta}, \bar{\theta}]$. Since $w$ vanishes over $(-\infty, \underline{\theta})$ and is affine over $(\bar{\theta}, \infty)$, it follows that $w$ is of locally bounded variation. Finally, for all $(p, \varepsilon) \in \mathbb{R} \times \mathbb{R}_{+}$, we have by (2) that

$$
w(p-\varepsilon)=w(p)+\varepsilon F(p-\varepsilon)-\int_{(p-\varepsilon, p] \cap[\underline{\theta}, \bar{\theta}]}[v(\theta)-p] d F(\theta),
$$

so that $\lim \sup _{\varepsilon \downarrow 0} w(p-\varepsilon)=w(p)-[v(p)-p] \mathbf{P}[\{p\}] \leq w(p)$ by Assumption 1. Since $w$ is right-continuous, it follows that it is also upper semicontinuous.

Step 2. Let $U(\theta) \equiv T(\theta)-\theta Q(\theta)$ for all $\theta \in\left[\underline{\theta}, \theta_{1}\right]$. Standard considerations imply that the incentive compatibility constraints (8) are equivalent to the two conditions that $U(\theta)=\int_{\theta}^{\theta_{1}} Q(\vartheta) d \vartheta+U\left(\theta_{1}\right)$ for all $\theta \in\left[\underline{\theta}, \theta_{1}\right]$ and that the function $Q$ be nonincreasing over $\left[\underline{\theta}, \theta_{1}\right]$ (see, for instance, Rochet (1985)). Clearly, at the optimum, the participation constraint (9) must be binding at $\theta_{1}$, so that $U\left(\theta_{1}\right)=0$. Substituting for $U(\theta)$ in the objective function, and using Fact 1 with $a(\theta)=F(\theta)$ and $b(\theta)=\int_{\theta}^{\theta_{1}} Q(\vartheta) d \vartheta$, we obtain that the problem (7)-(11) reduces to maximizing

$$
\int_{\left[\theta, \theta_{1}\right]}\{[v(\theta)-\theta] Q(\theta) d F(\theta)-F(\theta) Q(\theta) d \theta\}
$$

subject to the constraint that $Q$ be nonincreasing and to the additional constraints (10) and (11). Using Fact 1 with $a(\theta)=F(\theta)$ and $b(\theta)=\theta$, we obtain that

$$
\begin{aligned}
w(\theta) & =\int_{[\underline{\theta}, \theta]} v(\vartheta) d F(\vartheta)-\theta F(\theta) \\
& =\int_{[\underline{\theta}, \theta]}\{[v(\vartheta)-\vartheta] d F(\vartheta)-F(\vartheta) d \vartheta\}
\end{aligned}
$$


for all $\theta \in[\underline{\theta}, \infty)$. Hence, the objective function (13) can be more compactly rewritten as

$$
\int_{\left[\underline{\theta}, \theta_{1}\right]} Q(\theta) d w(\theta) .
$$

Step 3. Since $w$ is right-continuous and of bounded variation, we can decompose $w$ into its continuous part $w^{c}$ and its jump part $\Delta w$, and rewrite (14) as

$$
\int_{\left[\underline{\theta}, \theta_{1}\right]} Q(\theta) d w^{c}(\theta)+\sum_{\theta \in\left[\underline{\theta}, \theta_{1}\right]} Q(\theta) \Delta w(\theta),
$$

where, since $w$ is upper semicontinuous, $\Delta w(\theta) \equiv w(\theta)-w(\theta-) \geq 0$ for all $\theta \in\left[\underline{\theta}, \theta_{1}\right]$. As $Q$ is nonincreasing, there can be no loss in profit in assuming that $Q$ is left-continuous. Let then $Q^{+}$be the right-continuous regularization of $Q$ such that $Q^{+}\left(\theta_{1}\right)=Q_{1}$. Using Fact 1 with $a(\theta)=w(\theta)$ and $b(\theta)=Q(\underline{\theta})-$ $Q^{+}(\theta)$, we obtain that

$$
\begin{aligned}
& {\left[Q(\underline{\theta})-Q_{1}\right] w\left(\theta_{1}\right)} \\
& \quad=\int_{\left[\underline{\theta}, \theta_{1}\right]}\left\{w(\theta) d\left[Q(\underline{\theta})-Q^{+}\right](\theta)+[Q(\underline{\theta})-Q(\theta)] d w(\theta)\right\} .
\end{aligned}
$$

Using the fact that $w(\underline{\theta}-)=0$ yields

$$
\int_{\left[\underline{\theta}, \theta_{1}\right]} Q(\theta) d w(\theta)=Q_{1} w\left(\theta_{1}\right)+\int_{\left[\underline{\theta}, \theta_{1}\right]} w(\theta) d\left[Q(\underline{\theta})-Q^{+}\right](\theta) .
$$

Let $\mathbf{Q}$ be the Lebesgue-Stieltjes measure over $\left[\underline{\theta}, \theta_{1}\right]$ associated with the nondecreasing and right-continuous function $Q(\underline{\theta})-Q^{+}$. Since $Q^{+}\left(\theta_{1}\right)=Q_{1}$, the mass of $\mathbf{Q}$ is $Q(\underline{\theta})-Q_{1}$. Two cases must be distinguished. If $\theta_{0}>\underline{\theta}$, then $Q(\underline{\theta})=Q_{0}$ and the mass of $\mathbf{Q}$ is $Q_{0}-Q_{1}$; in addition, since $Q=Q_{0}$ over $\left[\underline{\theta}, \theta_{0}\right)$, $\mathbf{Q}$ does not charge $\left[\underline{\theta}, \theta_{0}\right)$. If $\theta_{0}=\underline{\theta}$, then $Q(\underline{\theta})$ is a control variable in $\left[Q_{1}, 1\right]$ and the mass of $\mathbf{Q}$ can take any value in $\left[0,1-Q_{1}\right]$. In any case, the maximum in (15) is reached by putting all the mass of $\mathbf{Q}$ on a maximum point of $w$ over $\left[\theta_{0}, \theta_{1}\right]$, and since the maximal value of $w$ over $[\underline{\theta}, \infty)$ is nonnegative, by setting $Q(\underline{\theta})=1$ if $\theta_{0}=\underline{\theta}$, which yields the profit (12). The result follows. Q.E.D.

Proof of Proposition 1: For each $i$, let $\left(q^{i}(\theta), t^{i}(\theta)\right)$ be the contract traded by type $\theta$ with buyer $i$, so that $T(\theta)=\sum_{i} t^{i}(\theta)$ and $Q(\theta)=\sum_{i} q^{i}(\theta)$, let $b^{i}(\theta) \equiv v(\theta) q^{i}(\theta)-t^{i}(\theta)$ be the profit earned by buyer $i$ when trading with type $\theta$, and let $U(\theta) \equiv T(\theta)-\theta Q(\theta)$ be the profit earned by type $\theta$. Observe that, given the menus offered by the sellers, the functions $q^{i}, t^{i}, b^{i}$, $Q, T$, and $U$ can be defined over the whole of $[\underline{\theta}, \infty)$, not only on the support of $\mathbf{P}$. As explained in Section 2.1, the function $\left(q^{i}, t^{i}\right):[\underline{\theta}, \infty) \rightarrow C^{i}$ can 
be chosen to be measurable. Moreover, incentive compatibility implies that $U(\theta)=\int_{\theta}^{\theta^{\prime}} Q(\vartheta) d \vartheta+U\left(\theta^{\prime}\right)$ for all $\left(\theta, \theta^{\prime}\right) \in[\underline{\theta}, \infty)^{2}$ and that the function $Q$ is nonincreasing over $[\underline{\theta}, \infty)$. Finally, for $\theta$ large enough, we must have $Q(\theta)<1$; otherwise, we would have $T(\theta) \geq \theta$ for all $\theta \geq \underline{\theta}$ by individual rationality, and thus $T(\theta)=\infty$ for all $\theta \geq \underline{\theta}$ by incentive compatibility, leading to a negatively infinite aggregate profit for the buyers, a contradiction. Therefore, $\theta_{0} \equiv \inf \{\theta \in[\underline{\theta}, \infty): Q(\theta)<1\}$ is well defined. The bulk of the proof consists in showing that $\theta_{0} \geq p^{*}$.

Suppose then, by way of contradiction, that $\theta_{0}<p^{*}$ and take some $\theta_{1} \in$ $\left(\theta_{0}, p^{*}\right)$ that is not an atom of $\mathbf{P}$; by construction, $Q<1$ in a neighborhood of $\theta_{1}$. We now construct a deviation that any buyer can employ. First, fix some number $\varepsilon \in\left(0,1-Q\left(\theta_{1}\right)\right)$, along with some differentiable, strictly positive, and strictly decreasing function $\chi_{\varepsilon}:\left[\theta_{1}, p^{*} \vee \bar{\theta}\right] \rightarrow[0, \varepsilon]$, with $\chi_{\varepsilon}\left(\theta_{1}\right)=\varepsilon$ and $\chi_{\varepsilon}^{\prime}<0$ over $\left(\theta_{1}, p^{*} \vee \bar{\theta}\right)$. Next, for each $\theta \in\left[\theta_{1}, p^{*} \vee \bar{\theta}\right]$, define $v_{\varepsilon}(\theta) \equiv$ $\varepsilon+\int_{\theta}^{p^{*} \vee \bar{\theta}} \chi_{\varepsilon}(\vartheta) d \vartheta$. Finally, for each $\theta \in\left[\theta_{1}, p^{*} \vee \bar{\theta}\right]$, define $\tau_{\varepsilon}(\theta) \equiv v_{\varepsilon}(\theta)+$ $\theta \chi_{\varepsilon}(\theta)$. It is straightforward to verify that the schedule $\left\{\left(\chi_{\varepsilon}(\theta), \tau_{\varepsilon}(\theta)\right): \theta \in\right.$ $\left.\left[\theta_{1}, p^{*} \vee \bar{\theta}\right]\right\}$ is strictly individually rational and strictly incentive compatible:

$$
\tau_{\varepsilon}(\theta)-\theta \chi_{\varepsilon}(\theta)> \begin{cases}0 & \forall \theta \in\left[\theta_{1}, p^{*} \vee \bar{\theta}\right], \\ \tau_{\varepsilon}\left(\theta^{\prime}\right)-\theta \chi_{\varepsilon}\left(\theta^{\prime}\right) & \forall\left(\theta, \theta^{\prime}\right) \in\left[\theta_{1}, p^{*} \vee \bar{\theta}\right]^{2}, \theta \neq \theta^{\prime}\end{cases}
$$

Now, consider what happens if some buyer $i$ offered, instead of his equilibrium menu $C^{i}$, the contracts

$$
\begin{aligned}
& c_{0}^{i} \equiv\left(q^{i}\left(\theta_{1}\right)+1-Q\left(\theta_{1}\right), t^{i}\left(\theta_{1}\right)+\theta_{1}\left[1-Q\left(\theta_{1}\right)\right]+v_{\varepsilon}\left(\theta_{1}\right)\right), \\
& c_{1}^{i}(\theta) \equiv\left(q^{i}(\theta)+\chi_{\varepsilon}(\theta), t^{i}(\theta)+\tau_{\varepsilon}(\theta)\right), \quad \theta \in\left[\theta_{1}, p^{*} \vee \bar{\theta}\right] .
\end{aligned}
$$

The following lemma, the proof of which can be found below, shows how the different types of the seller would react to this offer.

LEMMA 3: For $\varepsilon$ close enough to zero, if buyer $i$ offers the contracts (16) and (17), then types $\theta \in\left[\underline{\theta}, \theta_{1}\right)$ choose to trade $c_{0}^{i}$, while types $\theta \in\left(\theta_{1}, p^{*} \vee \bar{\theta}\right]$ choose to trade $c_{1}^{i}(\theta)$.

A potential problem with the contract offer (16) and (17) is that it does not necessarily constitute a compact menu of contracts, because the function $c_{1}^{i}$ defined by (17) may be discontinuous over $\left[\theta_{1}, p^{*} \vee \bar{\theta}\right]$. Yet, since $c_{1}^{i}$ is measurable, it follows from Lusin's theorem (Aliprantis and Border (1999, Theorem 10.8)) that for any $\varepsilon \in\left(0,1-Q\left(\theta_{1}\right)\right)$ there exists a compact subset $K_{\varepsilon}$ of $\left[\theta_{1}, p^{*} \vee \bar{\theta}\right]$ with $\mathbf{P}\left[\left[\theta_{1}, p^{*} \vee \bar{\theta}\right] \backslash K_{\varepsilon}\right]<\varepsilon$ such that the restriction of $c_{1}^{i}$ to $K_{\varepsilon}$ is continuous. It follows that

$$
C_{\varepsilon}^{i} \equiv\left\{(0,0), c_{0}^{i}\right\} \cup\left\{c_{1}^{i}(\theta): \theta \in K_{\varepsilon}\right\}
$$


is a compact menu.

From Lemma 3, if buyer $i$ deviates by offering the menu $C_{\varepsilon}^{i}$, types $\theta \in\left[\underline{\theta}, \theta_{1}\right)$ choose to trade $c_{0}^{i}$, while types $\theta \in K_{\varepsilon}$ choose to trade $c_{1}^{i}(\theta)$. We do not know a priori how type $\theta_{1}$ or types $\theta \in\left(\theta_{1}, p^{*} \vee \bar{\theta}\right] \backslash K_{\varepsilon}$ would react to buyer $i$ 's deviation. However, this only has a limited impact on buyer $i$ 's profit, because $\theta_{1}$ is not an atom of $\mathbf{P}$ and $\mathbf{P}\left[\left[\theta_{1}, p^{*} \vee \bar{\theta}\right] \backslash K_{\varepsilon}\right]<\varepsilon$. Formally, the change in buyer $i$ 's profit induced by this deviation is at least

$$
\begin{aligned}
& \int_{\left[\underline{\theta}, \theta_{1}\right]}\left\{\left[q^{i}\left(\theta_{1}\right)+1-Q\left(\theta_{1}\right)\right] v(\theta)-t^{i}\left(\theta_{1}\right)\right. \\
& \left.-\theta_{1}\left[1-Q\left(\theta_{1}\right)\right]-v_{\varepsilon}\left(\theta_{1}\right)-b^{i}(\theta)\right\} d F(\theta) \\
& \quad+\int_{K_{\varepsilon}}\left[v(\theta) \chi_{\varepsilon}(\theta)-\tau_{\varepsilon}(\theta)\right] \mathbf{P}(d \theta) \\
& +\varepsilon \inf _{(q, t, \theta) \in C_{\varepsilon}^{i} \times\left[\theta_{1}, p^{*} \vee \bar{\theta}\right] \backslash K_{\varepsilon}}\left\{v(\theta) q-t-b^{i}(\theta)\right\},
\end{aligned}
$$

which must at most be zero in equilibrium. Letting $\varepsilon$ go to zero and using the definition of $w$, we obtain that

$$
\left[q^{i}\left(\theta_{1}\right)+1-Q\left(\theta_{1}\right)\right] w\left(\theta_{1}\right) \leq \int_{\left[\underline{\theta}, \theta_{1}\right]}\left[t^{i}\left(\theta_{1}\right)-\theta_{1} q^{i}\left(\theta_{1}\right)+b^{i}(\theta)\right] d F(\theta) .
$$

Summing over $i$ and using the definition of $U\left(\theta_{1}\right)$ along with the fact that the buyers' aggregate profit $\sum_{i} b^{i}(\theta)$ is $[v(\theta)-\theta] Q(\theta)-U(\theta)$ for any type $\theta$ then yields

$$
\begin{aligned}
& \left\{Q\left(\theta_{1}\right)+n\left[1-Q\left(\theta_{1}\right)\right]\right\} w\left(\theta_{1}\right) \\
& \quad \leq \int_{\left[\underline{\theta}, \theta_{1}\right]}\left\{[v(\theta)-\theta] Q(\theta)-\left[U(\theta)-U\left(\theta_{1}\right)\right]\right\} d F(\theta) \\
& \quad=\int_{\left[\underline{\theta}, \theta_{1}\right]}\{[v(\theta)-\theta] Q(\theta) d F(\theta)-F(\theta) Q(\theta) d \theta\},
\end{aligned}
$$

where the equality follows from the fact that $U(\theta)-U\left(\theta_{1}\right)=\int_{\theta}^{\theta_{1}} Q(\vartheta) d \vartheta$ for all $\theta \in\left[\underline{\theta}, \theta_{1}\right]$ and from an integration by parts similar to that which led to (13); indeed, the right-hand side of (18) is nothing but (13). Now, since $Q$ is nonincreasing, $Q(\theta) \geq Q\left(\theta_{1}\right)$ for all $\theta \in\left[\underline{\theta}, \theta_{1}\right]$, and by definition of $\theta_{0}, Q(\theta)=1$ for all $\theta \in\left[\underline{\theta}, \theta_{0}\right)$. Thus, the buyers' aggregate profit on the right-hand side of (18) is at most equal to the value of problem (7)-(11) with $\left(\theta_{0}, \theta_{1}, Q_{0}, Q_{1}\right)=\left(\theta_{0}, \theta_{1}, 1, Q\left(\theta_{1}\right)\right)$, that is, by Lemma $1, Q\left(\theta_{1}\right) w\left(\theta_{1}\right)+$ $\left[1-Q\left(\theta_{1}\right)\right] \max _{\theta \in\left[\theta_{0}, \theta_{1}\right]}\{w(\theta)\}$. After substituting in (18) and simplifying as $Q\left(\theta_{1}\right)<1$, we finally obtain that

$$
n w\left(\theta_{1}\right) \leq \max _{\theta \in\left[\theta_{0}, \theta_{1}\right]}\{w(\theta)\} .
$$


Since this inequality holds for all $\theta_{1} \in C_{F}\left(\theta_{0}, p^{*}\right) \equiv\left\{\theta \in\left(\theta_{0}, p^{*}\right): F(\theta)=\right.$ $F(\theta-)\}$, we can take suprema to get

$$
n \sup _{\theta_{1} \in C_{F}\left(\theta_{0}, p^{*}\right)}\left\{w\left(\theta_{1}\right)\right\} \leq \sup _{\theta_{1} \in C_{F}\left(\theta_{0}, p^{*}\right)}\left\{\max _{\theta \in\left[\theta_{0}, \theta_{1}\right]}\{w(\theta)\}\right\} \leq \sup _{\theta \in\left[\theta_{0}, p^{*}\right)}\{w(\theta)\},
$$

which, since $C_{F}\left(\theta_{0}, p^{*}\right)$ is dense in $\left[\theta_{0}, p^{*}\right), w$ is right-continuous, and $n \geq 2$, implies that

$$
\sup _{\theta \in\left[\theta_{0}, p^{*}\right)}\{w(\theta)\} \leq 0 .
$$

This, however, contradicts the definition of $p^{*}$ as $\sup \{p \in \mathbb{R}: w(p)>0\}$, establishing that $\theta_{0} \geq p^{*}$, as claimed.

Since $Q$ is nonincreasing, it follows from the definition of $\theta_{0}$ as $\inf \{\theta \in$ $[\underline{\theta}, \infty): Q(\theta)<1\}$ that $Q=1$ over $\left[\underline{\theta}, p^{*}\right)$. In particular, we must have $T \geq$ $p^{*}$ over $\left[\underline{\theta}, p^{*}\right)$. If $p^{*} \geq \bar{\theta}$, we must also have $T \leq \mathbf{E}[v(\theta)]=p^{*}$; otherwise, the buyers' aggregate profit would be strictly negative. ${ }^{33}$ Hence, in that case, $(Q, T)=\left(1, p^{*}\right)$ over $\left[\underline{\theta}, p^{*}\right)$ and the buyers earn zero profit, which concludes the proof.

Now suppose that $p^{*}<\bar{\theta}$. Then the buyers' aggregate profit is at most equal to the value of problem (7)-(11) with $\left(\theta_{0}, \theta_{1}, Q_{0}, Q_{1}\right)=\left(p^{*}, \bar{\theta}, 1,0\right)$, that is, by Lemma 1 and the definition of $p^{*}, \max _{\theta \in\left[p^{*}, \bar{\theta}\right\}}\{w(\theta)\}=0$. Thus, each buyer earns zero profit in equilibrium. To determine $Q$ over $\left(p^{*}, \bar{\theta}\right]$, we can proceed as for (15). Specifically, if $Q^{+}$is the right-continuous regularization of $Q$, then the buyers' aggregate profit can be written as

$$
Q^{+}(\bar{\theta}) w(\bar{\theta})+\int_{\left[p^{*}, \bar{\theta}\right]} w(\theta) d\left[Q(\underline{\theta})-Q^{+}\right](\theta),
$$

where the integral in (19) ranges over $\left[p^{*}, \bar{\theta}\right]$ because $Q=1$ over $\left[\underline{\theta}, p^{*}\right)$, so that the Lebesgue-Stieltjes measure $\mathbf{Q}$ over $[\underline{\theta}, \infty)$ associated to the function $Q(\underline{\theta})-Q^{+}$does not charge $\left[\underline{\theta}, p^{*}\right)$. Since $w\left(p^{*}\right)=0$ and $w(p)<0$ if $p>p^{*}$ by Assumption 2, and since the buyers' aggregate profit is zero in equilibrium, we must have $Q^{+}(\bar{\theta})=0$, so that the mass of $\mathbf{Q}$ is $Q(\underline{\theta})$; as a result, it must be that $\mathbf{Q}=Q(\underline{\theta}) \boldsymbol{\delta}_{p^{*}}$; otherwise, the integral in (19) would be strictly negative. Thus, $Q=0$ over $\left(p^{*}, \bar{\theta}\right]$. To pin down aggregate transfers, observe first that $T \leq p^{*}$ over $\left[\underline{\theta}, p^{*}\right)$; otherwise, some types $\theta>p^{*}$ would find it profitable to sell their endowments, in contradiction with the fact that $Q=0$ over $\left(p^{*}, \bar{\theta}\right]$. Since, as observed above, $T \geq p^{*}$ over $\left[\underline{\theta}, p^{*}\right)$, it follows that $T=p^{*}$ over $\left[\underline{\theta}, p^{*}\right)$. By

\footnotetext{
${ }^{33}$ Recall that $p^{*}$ can be an atom of $\mathbf{P}$ only as long as $v\left(p^{*}\right)=p^{*}$, so that we always have $p^{*}=$ $\mathbf{E}\left[v(\theta) \mid \theta<p^{*}\right]$ if $p^{*}>\underline{\theta}$. Thus, in the present case, if $p^{*}=\bar{\theta}$, we have $\mathbf{E}[v(\theta) \mid \theta<\bar{\theta}]=\mathbf{E}[v(\theta)]$, and the buyers cannot make profits from trading with type $\bar{\theta}$.
} 
definition of $p^{*}$, this implies that the buyers' aggregate profit from trading with types $\theta<p^{*}$ is zero, see footnote 33. Finally, $T=0$ over $\left(p^{*}, \bar{\theta}\right.$ ], because types $\theta>p^{*}$ keep their endowments, so that $T \geq 0$ over $\left(p^{*}, \bar{\theta}\right]$, and some buyers would earn strictly negative profits if $T$ were to take strictly positive values over $\left(p^{*}, \bar{\theta}\right]$. Hence the result.

Q.E.D.

ProOF OF LeMma 3: The following notation will be useful. First, let

$$
\mathfrak{A}^{-i} \equiv\left\{\sum_{j \neq i}\left(q^{j}, t^{j}\right):\left(q^{j}, t^{j}\right) \in C^{j} \text { for all } j \neq i \text { and } \sum_{j \neq i} q^{j} \leq 1\right\}
$$

be the set of aggregate allocations that remain available if buyer $i$ withdraws his menu offer $C^{i}$. By construction, $\mathfrak{A}^{-i}$ is a compact set. Second, let

$$
\begin{aligned}
& z^{-i}(\theta, Q) \\
& \quad \equiv \max \left\{T^{-i}-\theta Q^{-i}:\left(Q^{-i}, T^{-i}\right) \in \mathfrak{A}^{-i} \text { and } Q^{-i} \leq Q\right\}
\end{aligned}
$$

be the highest profit type $\theta$ can earn from trading with buyers other than $i$ when her remaining stock is $Q$. Notice that $z^{-i}(\theta, Q)$ is nonnegative and nondecreasing with respect to $Q$. Fix $\theta_{1}$ as in the proof of Proposition 1 . The proof then goes through a series of steps.

Step 1. First, we show that each type $\theta \in\left[\theta_{1}, p^{*} \vee \bar{\theta}\right]$ strictly prefers $c_{1}^{i}(\theta)$ to not trading with buyer $i$ and to any other $c_{1}^{i}\left(\theta^{\prime}\right), \theta^{\prime} \neq \theta$. Indeed, in equilibrium, we have

$$
U(\theta)=T(\theta)-\theta Q(\theta)=t^{i}(\theta)-\theta q^{i}(\theta)+z^{-i}\left(\theta, 1-q^{i}(\theta)\right) .
$$

Therefore, a solution to the problem that defines $z^{-i}\left(\theta, 1-q^{i}(\theta)\right)$ is to trade $\left(Q^{-i}, T^{-i}\right) \equiv\left(Q(\theta)-q^{i}(\theta), T(\theta)-t^{i}(\theta)\right)$ with the buyers other than $i$. Given buyer $i$ 's deviation, if type $\theta \operatorname{trades} c_{1}^{i}(\theta)$, she earns a profit

$$
U_{\varepsilon}(\theta) \equiv t^{i}(\theta)+\tau_{\varepsilon}(\theta)-\theta\left[q^{i}(\theta)+\chi_{\varepsilon}(\theta)\right]+z^{-i}\left(\theta, 1-q^{i}(\theta)-\chi_{\varepsilon}(\theta)\right) .
$$

By construction, $\chi_{\varepsilon}(\theta)<1-Q\left(\theta_{1}\right)$. Hence, since $Q$ is nonincreasing, then

$$
1-q^{i}(\theta)-\chi_{\varepsilon}(\theta)>Q\left(\theta_{1}\right)-q^{i}(\theta) \geq Q(\theta)-q^{i}(\theta)=Q^{-i} .
$$

In particular, trading $\left(Q^{-i}, T^{-i}\right)$ with buyers other than $i$ remains a feasible choice in the problem that defines $z^{-i}\left(\theta, 1-q^{i}(\theta)-\chi_{\varepsilon}(\theta)\right)$. This implies that $z^{-i}\left(\theta, 1-q^{i}(\theta)-\chi_{\varepsilon}(\theta)\right)$ is at least as large as $z^{-i}\left(\theta, 1-q^{i}(\theta)\right)$; since $\chi_{\varepsilon}(\theta)>0$ and $z^{-i}(\theta, \cdot)$ is nondecreasing, these two terms must actually be equal. Therefore, using (22) and (23) along with the definition of $v_{\varepsilon}$, we get that $U_{\varepsilon}(\theta)=U(\theta)+v_{\varepsilon}(\theta)$. Since, by construction, $v_{\varepsilon}(\theta)>0$, it follows that $U_{\varepsilon}(\theta)>U(\theta)$ and thus type $\theta$ has a strict incentive to trade actively with 
buyer $i$. Now type $\theta$ could trade the contract $c_{1}^{i}\left(\theta^{\prime}\right)$ for some $\theta^{\prime} \neq \theta$, in which case she would earn a profit

$$
\begin{aligned}
u_{\varepsilon}\left(\theta, \theta^{\prime}\right) \equiv & t^{i}\left(\theta^{\prime}\right)+\tau_{\varepsilon}\left(\theta^{\prime}\right)-\theta\left[q^{i}\left(\theta^{\prime}\right)+\chi_{\varepsilon}\left(\theta^{\prime}\right)\right] \\
& +z^{-i}\left(\theta, 1-q^{i}\left(\theta^{\prime}\right)-\chi_{\varepsilon}\left(\theta^{\prime}\right)\right) .
\end{aligned}
$$

Because $\chi_{\varepsilon}\left(\theta^{\prime}\right)>0$,

$$
z^{-i}\left(\theta, 1-q^{i}\left(\theta^{\prime}\right)-\chi_{\varepsilon}\left(\theta^{\prime}\right)\right) \leq z^{-i}\left(\theta, 1-q^{i}\left(\theta^{\prime}\right)\right) .
$$

Moreover, since the schedule $\left\{\left(\chi_{\varepsilon}(\theta), \tau_{\varepsilon}(\theta)\right): \theta \in\left[\theta_{1}, p^{*} \vee \bar{\theta}\right]\right\}$ is strictly incentive compatible,

$$
\tau_{\varepsilon}\left(\theta^{\prime}\right)-\theta \chi_{\varepsilon}\left(\theta^{\prime}\right)<v_{\varepsilon}(\theta) .
$$

Finally, incentive compatibility on the equilibrium path imposes that

$$
t^{i}\left(\theta^{\prime}\right)-\theta q^{i}\left(\theta^{\prime}\right)+z^{-i}\left(\theta, 1-q^{i}\left(\theta^{\prime}\right)\right) \leq U(\theta) .
$$

Summing (25)-(27) and substituting in (24) yield $u_{\varepsilon}\left(\theta, \theta^{\prime}\right)<U(\theta)+v_{\varepsilon}(\theta)=$ $U_{\varepsilon}(\theta)$, and thus type $\theta$ strictly prefers $c_{1}^{i}(\theta)$ to any $c_{1}^{i}\left(\theta^{\prime}\right), \theta^{\prime} \neq \theta$.

Step 2. Second, we show that each type $\theta \in\left(\theta_{1}, p^{*} \vee \bar{\theta}\right]$ strictly prefers $c_{1}^{i}(\theta)$ to $c_{0}^{i}$. We know from Step 1 that any such type $\theta$ strictly prefers $c_{1}^{i}(\theta)$ to $c_{1}^{i}\left(\theta_{1}\right)$. Moreover, trading $c_{0}^{i}$ is equivalent to trading $c_{1}^{i}\left(\theta_{1}\right)$ along with the contract $\left(1-Q\left(\theta_{1}\right)-\chi_{\varepsilon}\left(\theta_{1}\right), \theta_{1}\left[1-Q\left(\theta_{1}\right)-\chi_{\varepsilon}\left(\theta_{1}\right)\right]\right.$, which has unit price $\theta_{1}<\theta$ and, moreover, restricts the trades type $\theta$ can do with buyers other than $i$. Hence, each type $\theta \in\left(\theta_{1}, \bar{\theta}\right]$ strictly prefers $c_{1}^{i}\left(\theta_{1}\right)$ to $c_{0}^{i}$.

Step 3. Third, we show that type $\theta_{1}$ is indifferent between $c_{0}^{i}$ and $c_{1}^{i}\left(\theta_{1}\right)$. Arguing as in Step 2, we get that type $\theta_{1}$ weakly prefers $c_{1}^{i}\left(\theta_{1}\right)$ to $c_{0}^{i}$. On the other hand, type $\theta_{1}$ may trade $c_{0}^{i}$ with buyer $i$ and $\left(Q\left(\theta_{1}\right)-q^{i}\left(\theta_{1}\right), T\left(\theta_{1}\right)-t^{i}\left(\theta_{1}\right)\right)$ with buyers other than $i$, and end up with a profit equal to $U\left(\theta_{1}\right)+v_{\varepsilon}\left(\theta_{1}\right)$, which, by Step 1 , is exactly the profit $U_{\varepsilon}\left(\theta_{1}\right)$ that she would earn by trading $c_{1}^{i}\left(\theta_{1}\right)$. This proves our claim. This also shows that a solution to type $\theta_{1}$ 's profit maximization problem, once she has traded $c_{0}^{i}$, consists in selling the remaining part $Q\left(\theta_{1}\right)-q^{i}\left(\theta_{1}\right)$ of her endowment to buyers other than $i$.

Step 4. Fourth, we show that, if $\varepsilon$ is close enough to zero, each type $\theta \in\left[\underline{\theta}, \theta_{1}\right)$ strictly prefers $c_{0}^{i}$ to not trading with buyer $i$ and to any $c_{1}^{i}\left(\theta^{\prime}\right)$. From Step 3 , we know that if she trades $c_{0}^{i}$, type $\theta_{1}$ may optimally choose to sell the remaining part of her endowment to buyers other than $i$. Because the seller's preferences satisfy a strict single-crossing condition, this must also be the case for any type $\theta<\theta_{1}$. Hence, the profit of type $\theta$ when she trades $c_{0}^{i}$ must be equal to

$$
U_{\varepsilon}(\theta) \equiv U_{\varepsilon}\left(\theta_{1}\right)+\theta_{1}-\theta=U\left(\theta_{1}\right)+v_{\varepsilon}\left(\theta_{1}\right)+\theta_{1}-\theta .
$$

Since $U\left(\theta_{1}\right)=U(\theta)-\int_{\theta}^{\theta_{1}} Q(\vartheta) d \vartheta$ and $Q \leq 1$, we have $U\left(\theta_{1}\right) \geq U(\theta)-$ $\theta_{1}+\theta$. Hence, (28) implies that $U_{\varepsilon}(\theta) \geq U(\theta)+v_{\varepsilon}\left(\theta_{1}\right)$. Since, by construction, 
$v_{\varepsilon}\left(\theta_{1}\right)>0$, it follows that $U_{\varepsilon}(\theta)>U(\theta)$ and thus type $\theta$ has a strict incentive to trade actively with buyer $i$. Now, type $\theta$ could trade some contract $c_{1}^{i}\left(\theta^{\prime}\right)$, in which case she would earn a profit $u_{\varepsilon}\left(\theta, \theta^{\prime}\right)$ as in (24). Using (25) and (27), we obtain that

$$
u_{\varepsilon}\left(\theta, \theta^{\prime}\right) \leq U(\theta)+\tau_{\varepsilon}\left(\theta^{\prime}\right)-\theta \chi_{\varepsilon}\left(\theta^{\prime}\right)=U(\theta)+v_{\varepsilon}\left(\theta^{\prime}\right)+\left(\theta^{\prime}-\theta\right) \chi_{\varepsilon}\left(\theta^{\prime}\right) .
$$

Consider the function defined by $\varphi_{\varepsilon}\left(\theta^{\prime}\right) \equiv v_{\varepsilon}\left(\theta^{\prime}\right)+\left(\theta^{\prime}-\theta\right) \chi_{\varepsilon}\left(\theta^{\prime}\right)$. By construction, $\varphi_{\varepsilon}$ is continuous over $\left[\theta_{1}, p^{*} \vee \bar{\theta}\right]$ and differentiable over $\left(\theta_{1}, p^{*} \vee \bar{\theta}\right)$, with $\varphi_{\varepsilon}^{\prime}\left(\theta^{\prime}\right)=\left(\theta^{\prime}-\theta\right) \chi_{\varepsilon}^{\prime}\left(\theta^{\prime}\right)<0$ for all $\theta^{\prime} \in\left(\theta_{1}, p^{*} \vee \bar{\theta}\right)$. Thus, $\varphi_{\varepsilon}$ is strictly decreasing over $\left[\theta_{1}, p^{*} \vee \bar{\theta}\right]$ and from (29), we have

$$
u_{\varepsilon}\left(\theta, \theta^{\prime}\right) \leq U(\theta)+v_{\varepsilon}\left(\theta_{1}\right)+\left(\theta_{1}-\theta\right) \chi_{\varepsilon}\left(\theta_{1}\right) .
$$

It follows from (28) and (30) that to show, for $\varepsilon$ close enough to zero, that any type $\theta \in\left[\underline{\theta}, \theta_{1}\right)$ strictly prefers $c_{0}^{i}$ to any $c_{1}^{i}\left(\theta^{\prime}\right)$, we only need to establish that

$$
U(\theta)+\left(\theta_{1}-\theta\right) \chi_{\varepsilon}\left(\theta_{1}\right)<U\left(\theta_{1}\right)+\theta_{1}-\theta
$$

or, equivalently,

$$
\int_{\theta}^{\theta_{1}} Q(\vartheta) d \vartheta<\left(\theta_{1}-\theta\right)\left[1-\chi_{\varepsilon}\left(\theta_{1}\right)\right]
$$

for any such $\varepsilon$ and $\theta$. Since $Q$ is nonincreasing and $\chi_{\varepsilon}\left(\theta_{1}\right)=\varepsilon$ can be chosen arbitrarily close to zero, this holds if and only if

$$
\frac{1}{\theta_{1}-\underline{\theta}} \int_{\underline{\theta}}^{\theta_{1}} Q(\vartheta) d \vartheta<1
$$

which indeed is true because $Q \leq 1$ everywhere and $Q<1$ in a left neighborhood of $\theta_{1}$. The result follows.

Q.E.D.

Proof of Proposition 2: The result is immediate when $p^{*}=\underline{\theta}$, because even a monopsonist could not then extract any profit from the seller; only type $\underline{\theta}$ can then trade actively in equilibrium, and any contract featuring a strictly positive quantity for type $\underline{\theta}$ must have unit price $p^{*}=\underline{\theta}$, so as not to attract types $\theta>\underline{\theta}$.

Suppose now that $p^{*}>\underline{\theta}$. The proof then goes through a series of steps.

Step 1. Given the menus offered, any best response of the seller leads to aggregate trades $\left(1, p^{*}\right)$ for types $\theta<p^{*}$ and $(0,0)$ for types $\theta>p^{*}$. The behavior of type $p^{*}$ is irrelevant to the buyers' profits, either because $p^{*}$ is not an atom or, if it is, because then $v\left(p^{*}\right)=p^{*}$. Assuming that in equilibrium each buyer trades the same quantity with each type or, alternatively, that the seller trades with a single buyer, then all buyers earn zero profit, as $p^{*}=\mathbf{E}\left[v(\theta) \mid \theta \leq p^{*}\right]$ by (3). 
Step 2. Since any quantity can be sold at unit price $p^{*}$, each type $\theta \leq p^{*}$ attempts to maximize

$$
t-\theta q+\left(p^{*}-\theta\right)(1-q)=t-p^{*} q+p^{*}-\theta
$$

over the set of contracts $(q, t)$ offered by the deviating buyer. We can therefore construct the seller's strategy in such a way that each type $\theta \leq p^{*}$ selects the same contract $(\underline{q}, \underline{t})$ from the deviating buyer's menu. We must have $\underline{t} \geq p^{*} \underline{q}$; otherwise, the seller would be strictly better off selling the quantity $q^{*}$ to the other buyers at unit price $p^{*}$. Since $p^{*}=\mathbf{E}\left[v(\theta) \mid \theta \leq p^{*}\right]$, this implies that no buyer can deviate and make profits with types $\theta \leq p^{*}$. This concludes the proof if $p^{*} \geq \bar{\theta}$.

Step 3. If $\bar{\theta}>p^{*}$, a deviating buyer may also attempt to attract some types $\theta>p^{*}$. Over this set of types, he effectively acts as a monopsonist, since none of them has an incentive to sell to the other buyers at unit price $p^{*}$. Now take any contract $(q, t)$ in the deviating buyer's menu and suppose that $q>q$, where $(q, \underline{t})$ is constructed as in Step 2 . Then, since clearly $\underline{t}-p^{*} q \geq t-p^{*} q$, we a fortiori have $t-\theta q>t-\theta q$ for all $\theta>p^{*}$, so that each type $\theta>p^{*}$ would rather trade $(q, \underline{t})$ than $(q, t)$. It follows that types $\theta>p^{*}$ sell at most $q$ to the deviating buyer. An upper bound to the deviating buyer's profit is thus obtained by maximizing

$$
\int_{[\theta, \bar{\theta}]}[v(\theta) q(\theta)-t(\theta)] d F(\theta),
$$

subject to the seller's incentive compatibility and individual rationality constraints

$$
\begin{aligned}
& \underline{t}-p^{*} \underline{q} \geq t(\theta)-p^{*} q(\theta) \quad \forall \theta \in\left(p^{*}, \bar{\theta}\right], \\
& t(\theta)-\theta q(\theta) \geq \begin{cases}t\left(\theta^{\prime}\right)-\theta q\left(\theta^{\prime}\right) & \forall\left(\theta, \theta^{\prime}\right) \in\left(p^{*}, \bar{\theta}\right] \times[\underline{\theta}, \bar{\theta}], \\
0 & \forall \theta \in\left(p^{*}, \bar{\theta}\right],\end{cases}
\end{aligned}
$$

and to the two additional constraints that

$$
\begin{aligned}
& \left(q\left(\theta^{\prime}\right), t\left(\theta^{\prime}\right)\right)=(\underline{q}, \underline{t}) \quad \forall \theta^{\prime} \in\left[\underline{\theta}, p^{*}\right], \\
& \underline{q} \geq q(\theta) \quad \forall \theta \in\left(p^{*}, \bar{\theta}\right] .
\end{aligned}
$$

Constraints (31) and (35) imply that

$$
\underline{t}-\theta^{\prime} \underline{q} \geq t(\theta)-\theta^{\prime} q(\theta) \quad \forall\left(\theta, \theta^{\prime}\right) \in\left(p^{*}, \bar{\theta}\right] \times\left[\underline{\theta}, p^{*}\right] .
$$

Together with (32) and (34), this implies that the schedule $\{(q(\theta), t(\theta)): \theta \in$ $[\underline{\theta}, \bar{\theta}]\}$ is incentive compatible:

$$
t(\theta)-\theta q(\theta) \geq t\left(\theta^{\prime}\right)-\theta q\left(\theta^{\prime}\right) \quad \forall\left(\theta, \theta^{\prime}\right) \in[\underline{\theta}, \bar{\theta}]^{2} .
$$


Moreover, it follows from (33) and (34), along with the fact that $\underline{t} \geq p^{*} \underline{q}$, that this schedule is individually rational:

$$
t(\theta)-\theta q(\theta) \geq 0 \quad \forall\left(\theta, \theta^{\prime}\right) \in[\underline{\theta}, \bar{\theta}]^{2} .
$$

Taking into account constraint (34), we therefore obtain that the deviating buyer's profit is at most equal to the value of problem (7)-(11) with $\left(\theta_{0}, \theta_{1}, Q_{0}, Q_{1}\right)=\left(p^{*}, \bar{\theta}, \underline{q}, 0\right)$, that is, by Lemma $1, \underline{q} \max _{\theta \in\left[p^{*}, \bar{\theta}\right]}\{w(\theta)\}=0$. Hence the result.

Q.E.D.

ProOf OF Proposition 3: The result is obvious when $p^{*}=\underline{\theta}$. Suppose then that $p^{*}>\underline{\theta}$ and that some buyer $i$ offers a contract $c^{i}=\left(q^{i}, t^{i}\right)$ at unit price $t^{i} / q^{i}>p^{*}$ in equilibrium. We must have $q^{i}<1$; otherwise, $c^{i}$ would give types $\theta<t^{i}$ more than their equilibrium profit. Now any other buyer $j$ could offer a menu consisting of the no-trade contract and of the contract

$$
c^{j}(\varepsilon) \equiv\left(1-q^{i},\left(p^{*}-\varepsilon\right)\left(1-q^{i}\right)\right)
$$

for some $\varepsilon \in\left(0,\left(t^{i}-p^{*} q^{i}\right) /\left(1-q^{i}\right)\right)$ such that $p^{*}-\varepsilon$ is not an atom of $\mathbf{P}$; by definition of $p^{*}$, along with the fact that $p^{*}>\underline{\theta}$, we can furthermore choose $\varepsilon$ so that $w\left(p^{*}-\varepsilon\right)>0$. If both $c^{i}$ and $c^{j}(\varepsilon)$ were available, each type $\theta<p^{*}-\varepsilon$ would sell her whole endowment at price $t^{i}+\left(p^{*}-\varepsilon\right)\left(1-q^{i}\right)$ by trading $c^{i}$ with buyer $i$ and $c^{j}(\varepsilon)$ with buyer $j$, thereby increasing her profit by a strictly positive amount $t^{i}-p^{*} q^{i}-\varepsilon\left(1-q^{i}\right)$ compared to what she earns in equilibrium. By contrast, types $\theta>p^{*}-\varepsilon$ do not gain by trading $c^{j}(\varepsilon)$ with buyer $j$, since the unit price at which this contract is issued is too low from their point of view. Because $p^{*}-\varepsilon$ is not an atom of $\mathbf{P}$, buyer $j$ 's equilibrium profit must thus at least be

$$
\int_{\left[\theta, p^{*}-\varepsilon\right]}\left[v(\theta)-p^{*}+\varepsilon\right]\left(1-q^{i}\right) d F(\theta)=\left(1-q^{i}\right) w\left(p^{*}-\varepsilon\right),
$$

which is strictly positive given $q^{i}<1$ and the choice of $\varepsilon$. This, however, is impossible, because, by Proposition 1, each buyer earns zero profit in equilibrium. Hence, no contract can be issued, and a fortiori traded, at a price above $p^{*}$ in equilibrium. We now show that this implies that no contract can be traded at a price different from $p^{*}$ in equilibrium. To see this, suppose first that a contract with unit price below $p^{*}$ is traded by some type $\theta<p^{*}$ in equilibrium. Then since by Proposition 1 , the aggregate allocation traded by type $\theta$ is $\left(1, p^{*}\right)$, a contract with unit price above $p^{*}$ must be traded in equilibrium, a contradiction. There only remains the possibility that a contract with unit price below $p^{*}$ is traded by type $p^{*}$ in equilibrium. (Of course, this argument is needed only if $p^{*}$ belongs to the support of $\mathbf{P}$.) However, since type $p^{*}$ earns zero profit, 
this would again imply that a contract with unit price above $p^{*}$ is traded in equilibrium, a contradiction. The result follows.

Q.E.D.

Proof of Proposition 4: Fix some equilibrium and some buyer $i$, and define the set $\mathfrak{A}^{-i}$ as in (20). We must show that the aggregate allocation $\left(1, p^{*}\right)$ traded by types $\theta<p^{*}$ belongs to $\mathfrak{A}^{-i}$. If not, then since $\mathfrak{A}^{-i}$ is compact, there exists an open set of $[0,1] \times \mathbb{R}_{+}$that contains $\left(1, p^{*}\right)$ and that does not intersect $\mathfrak{A}^{-i}$. Moreover, any allocation $\left(Q^{-i}, T^{-i}\right) \in \mathfrak{A}^{-i}$ is such that $T^{-i} \leq p^{*} Q^{-i}$ by Proposition 3. For each $(\theta, Q) \in[\underline{\theta}, \infty) \times[0,1]$, define $z^{-i}(\theta, Q)$ as in $(21)$. For $\varepsilon$ strictly positive and close enough to zero, any solution to the maximization problem that defines $z^{-i}\left(p^{*}-\varepsilon, 1\right)$ must be such that the quantity traded by type $p^{*}-\varepsilon$ with buyers other than $i$ is bounded away from 1 ; otherwise, there would exist a sequence $\left\{\varepsilon_{n}\right\}_{n \geq 1}$ converging to zero and a sequence $\left\{\left(Q^{-i}\left(p^{*}-\right.\right.\right.$ $\left.\left.\left.\varepsilon_{n}, 1\right), T^{-i}\left(p^{*}-\varepsilon_{n}, 1\right)\right)\right\}_{n \geq 1}$ in $\mathfrak{A}^{-i}$ such that the sequence $\left\{Q^{-i}\left(p^{*}-\varepsilon_{n}, 1\right)\right\}_{n \geq 1}$ converges to 1 and

$$
T^{-i}\left(p^{*}-\varepsilon_{n}, 1\right)-\left(p^{*}-\varepsilon_{n}\right) Q^{-i}\left(p^{*}-\varepsilon_{n}, 1\right) \geq 0
$$

for all $n \geq 1$. Taking limits as $n$ goes to infinity and using the fact $\mathfrak{A}^{-i}$ is compact, this would imply that the seller can trade her whole endowment with buyers other than $i$ at a price at least $p^{*}$, a contradiction. Let $\left(\bar{Q}^{-i}\left(p^{*}-\varepsilon, 1\right), \bar{T}^{-i}\left(p^{*}-\right.\right.$ $\varepsilon, 1))$ be the solution to the maximization problem that defines $z^{-i}\left(p^{*}-\varepsilon, 1\right)$ with highest quantity traded. From the above argument, we can choose $\varepsilon$ so that $\bar{Q}^{-i}\left(p^{*}-\varepsilon, 1\right)<1$. We can further choose $\varepsilon$ so that $p^{*}-\varepsilon$ is not an atom of $\mathbf{P}$ and, by definition of $p^{*}$ along with the fact that $p^{*}>\underline{\theta}$, so that $w\left(p^{*}-\right.$ $\varepsilon)>0$. Buyer $i$ could offer a menu consisting of the no-trade contract and of the contract

$$
c^{i}(\varepsilon) \equiv\left(1-\bar{Q}^{-i}\left(p^{*}-\varepsilon, 1\right),\left(p^{*}-\varepsilon\right)\left[1-\bar{Q}^{-i}\left(p^{*}-\varepsilon, 1\right)\right]\right) .
$$

Consider any type $\theta<p^{*}-\varepsilon$ and let $\left(Q^{-i}(\theta, 1), T^{-i}(\theta, 1)\right)$ be a solution to the maximization problem that defines $z^{-i}(\theta, 1)$. By incentive compatibility, $Q^{-i}(\theta, 1) \geq \bar{Q}^{-i}\left(p^{*}-\varepsilon, 1\right)$. If $Q^{-i}(\theta, 1)=\bar{Q}^{-i}\left(p^{*}-\varepsilon, 1\right)$ and thus $T^{-i}(\theta, 1)=\bar{T}^{-i}\left(p^{*}-\varepsilon, 1\right)$, type $\theta$ could sell her whole endowment at price $T^{-i}(\theta, 1)+\left(p^{*}-\varepsilon\right)\left[1-\bar{Q}^{-i}\left(p^{*}-\varepsilon, 1\right)\right]$ by trading $c^{i}(\varepsilon)$ with buyer $i$ and $\left(Q^{-i}(\theta, 1), T^{-i}(\theta, 1)\right)$ with buyers other than $i$, thereby increasing her profit by a strictly positive amount $\left(p^{*}-\varepsilon-\theta\right)\left[1-\bar{Q}^{-i}\left(p^{*}-\varepsilon, 1\right)\right]$ compared to what she could earn from trading with buyers other than $i$ only. If $Q^{-i}(\theta, 1)>$ $\bar{Q}^{-i}\left(p^{*}-\varepsilon, 1\right)$, we have

$$
\begin{gathered}
\bar{T}^{-i}\left(p^{*}-\varepsilon, 1\right)-\left(p^{*}-\varepsilon\right) \bar{Q}^{-i}\left(p^{*}-\varepsilon, 1\right) \\
>T^{-i}(\theta, 1)-\left(p^{*}-\varepsilon\right) Q^{-i}(\theta, 1)
\end{gathered}
$$


by definition of $\bar{Q}^{-i}\left(p^{*}-\varepsilon, 1\right)$, from which it follows that

$$
\begin{aligned}
& \bar{T}^{-i}\left(p^{*}-\varepsilon, 1\right)+\left(p^{*}-\varepsilon\right)\left[1-\bar{Q}^{-i}\left(p^{*}-\varepsilon, 1\right)\right] \\
& \quad>T^{-i}(\theta, 1)+\left(p^{*}-\varepsilon\right)\left[1-Q^{-i}(\theta, 1)\right] \\
& \quad \geq T^{-i}(\theta, 1)+\theta\left[1-Q^{-i}(\theta, 1)\right]
\end{aligned}
$$

and finally that

$$
\begin{aligned}
& \bar{T}^{-i}\left(p^{*}-\varepsilon, 1\right)+\left(p^{*}-\varepsilon\right)\left[1-\bar{Q}^{-i}\left(p^{*}-\varepsilon, 1\right)\right]-\theta \\
& \quad>T^{-i}(\theta, 1)-\theta Q^{-i}(\theta, 1) .
\end{aligned}
$$

Thus, by trading $c^{i}(\varepsilon)$ with buyer $i$ and $\left(\bar{Q}^{-i}\left(p^{*}-\varepsilon, 1\right), \bar{T}^{-i}\left(p^{*}-\varepsilon, 1\right)\right)$ with buyers other than $i$, type $\theta$ would strictly increase her profit compared to what she could earn from trading with the buyers other than $i$ only. It follows that types $\theta<p^{*}-\varepsilon$ would trade $c^{i}(\varepsilon)$ if this contract were offered by buyer $i$. By contrast, types $\theta>p^{*}-\varepsilon$ do not gain by trading $c^{i}(\varepsilon)$ with buyer $i$, since the unit price at which this contract is issued is too low from their point of view. Because $p^{*}-\varepsilon$ is not an atom of $\mathbf{P}$, buyer $i$ 's equilibrium profit must thus at least be

$$
\begin{aligned}
& \int_{\left[\underline{\left.\theta, p^{*}-\varepsilon\right]}\right.}\left[v(\theta)-p^{*}+\varepsilon\right]\left[1-\bar{Q}^{-i}\left(p^{*}-\varepsilon, 1\right)\right] d F(\theta) \\
& \quad=\left[1-\bar{Q}^{-i}\left(p^{*}-\varepsilon, 1\right)\right] w\left(p^{*}-\varepsilon\right),
\end{aligned}
$$

which is strictly positive given $\bar{Q}^{-i}\left(p^{*}-\varepsilon, 1\right)<1$ and the choice of $\varepsilon$. This, however, is impossible, because, by Proposition 1 , each buyer earns zero profit in equilibrium. Hence the result.

Q.E.D.

ProOF OF Proposition 5: Fix some equilibrium and some buyer $i$, and define the function $z^{-i}$ as in (21). The following lemma, the proof of which can be found below, is key to the result.

LEMMA 4: For each $Q \in[0,1]$, the mapping $\theta \mapsto z^{-i}(\theta, Q)+\theta Q$ is nondecreasing over $[\underline{\theta}, \infty)$. Moreover, if this mapping is constant over some open interval of types, then for any type $\theta$ in this interval and for any solution $\left(Q^{-i}(\theta, Q), T^{-i}(\theta, Q)\right)$ to the maximization problem that defines $z^{-i}(\theta, Q)$, we have $Q^{-i}(\theta, Q)=Q$, so that there exists an aggregate allocation in $\mathfrak{A}^{-i}$ that allows the seller to exactly trade the quantity $Q$.

Given Lemma 4, it is enough to show that for each $Q_{0}$ close enough to zero, the mapping $\theta \mapsto z^{-i}\left(\theta, Q_{0}\right)+\theta Q_{0}$ is constant over some interval of types. To see this, fix some $Q_{0} \in(0,1)$ along with some $\theta_{0} \in\left(\underline{\theta}, p^{*}\right)$ that satisfies (5); we 
can without loss of generality assume that $\theta_{0}$ is not an atom of $\mathbf{P}$. Suppose that for all $\left(\theta^{\prime}, \theta^{\prime \prime}\right) \in[\underline{\theta}, \bar{\theta}]^{2}$ such that $\theta^{\prime}<\theta_{0}<\theta^{\prime \prime}$,

$$
z^{-i}\left(\theta^{\prime}, Q_{0}\right)+\theta^{\prime} Q_{0}<z^{-i}\left(\theta_{0}, Q_{0}\right)+\theta_{0} Q_{0}<z^{-i}\left(\theta^{\prime \prime}, Q_{0}\right)+\theta^{\prime \prime} Q_{0} .
$$

Then buyer $i$ could offer a menu consisting of the no-trade contract and of a contract $\left(1-Q_{0}, t_{0}\right)$ such that type $\theta_{0}$ is indifferent between trading the contract $\left(1-Q_{0}, t_{0}\right)$ with buyer $i$ along with some aggregate allocation in $\mathfrak{A}^{-i}$ with buyers other than $i$, and trading with the latter only, and therefore earn her equilibrium profit as shown in Proposition 4:

$$
t_{0}-\theta_{0}\left(1-Q_{0}\right)+z^{-i}\left(\theta_{0}, Q_{0}\right)=p^{*}-\theta_{0}
$$

Now, from (36), types $\theta>\theta_{0}$ strictly prefer accepting buyer $i$ 's offer to selling their whole endowment at price $p^{*}$ to buyers other than $i$, while types $\theta<\theta_{0}$ strictly prefer the latter option. As for types $\theta>p^{*}$, they satisfy $z^{-i}\left(\theta, Q_{0}\right)=0$ since they earn zero profit in equilibrium. Hence, any such type accepts buyer $i$ 's offer if $t_{0}>\theta\left(1-Q_{0}\right)$ or, equivalently, $\theta<\theta_{1}$, where $\theta_{1}$ is implicitly defined by

$$
t_{0}=\theta_{1}\left(1-Q_{0}\right)=\theta_{0}\left(1-Q_{0}\right)+p^{*}-\theta_{0}-z^{-i}\left(\theta_{0}, Q_{0}\right)
$$

It is easily checked that $\theta_{1} \geq p^{*}$ if and only if $\left(p^{*}-\theta_{0}\right) Q_{0} \geq z^{-i}\left(\theta_{0}, Q_{0}\right)$, which is indeed the case since, by Proposition 3, no contract is issued at a price above $p^{*}$ in equilibrium. It thus follows that the contract $\left(1-Q_{0}, t_{0}\right)$ offered by buyer $i$ attracts all types $\theta \in\left(\theta_{0}, \theta_{1}\right)$, with $\theta_{0}<p^{*} \leq \theta_{1}$, that types $\theta_{0}$ and $\theta_{1}$ are indifferent, and that all other types reject buyer $i$ 's offer. Because $\theta_{0}$ is not an atom of $\mathbf{P}$, buyer $i$ 's equilibrium profit must thus at least be

$$
\begin{aligned}
& \int_{\left[\theta_{0}, p^{*}\right)}\left[v(\theta)\left(1-Q_{0}\right)-t_{0}\right] d F(\theta) \\
& \quad+\left\{\left[v\left(p^{*}\right)\left(1-Q_{0}\right)-t_{0}\right] \mathbf{P}\left[\left\{p^{*}\right\}\right]\right\} \wedge 0+O\left(\theta_{1}-p^{*}\right)
\end{aligned}
$$

where the mapping $\varepsilon \mapsto O(\varepsilon) / \varepsilon$ is bounded in a neighborhood of zero. Now, let $Q_{0}$ go to zero. Then $z^{-i}\left(\theta_{0}, Q_{0}\right)$ goes to zero as $\left(p^{*}-\theta_{0}\right) Q_{0} \geq$ $z^{-i}\left(\theta_{0}, Q_{0}\right) \geq 0$, so that, by (37), $\theta_{1}$ and $t_{0}$ go to $p^{*}$. Two cases can then arise. If $p^{*}$ is not an atom of $\mathbf{P}$, then $\mathbf{P}\left[\left\{p^{*}\right\}\right]=0$ and the limit of (38) is $\int_{\left[\theta_{0}, p^{*}\right]}\left[v(\theta)-p^{*}\right] d F(\theta)$. If $p^{*}$ is an atom of $\mathbf{P}$, then from the definition of $p^{*}$ along with the right-continuity and upper semicontinuity of $w, v\left(p^{*}\right)=p^{*}$; it follows that $v\left(p^{*}\right)\left(1-Q_{0}\right)-t_{0}$ goes to zero as $Q_{0}$ goes to zero, and the limit of (38) is again $\int_{\left[\theta_{0}, p^{*}\right]}\left[v(\theta)-p^{*}\right] d F(\theta)$. Finally, recall that $\theta_{0}$ was chosen so that $\int_{\left[\theta_{0}, p^{*}\right]}\left[v(\theta)-p^{*}\right] d F(\theta)$ is strictly positive. This, however, is impossible, because, by Proposition 1 , each buyer earns zero profit in equilibrium. Thus, for each $Q_{0}$ close enough to zero, the mapping $\theta \mapsto z^{-i}\left(\theta, Q_{0}\right)+\theta Q_{0}$ must be 
constant over some open interval of types, and Lemma 4 applies. The result follows.

Q.E.D.

Proof of Lemma 4: Fix $\left(Q^{-i}, T^{-i}\right) \in \mathfrak{A}^{-i}$. Observe that as long as $Q^{-i} \leq Q$ and $\theta^{\prime} \geq \theta$, then

$$
T^{-i}-\theta^{\prime} Q^{-i}=T^{-i}-\theta Q^{-i}+\left(\theta-\theta^{\prime}\right) Q^{-i} \geq T^{-i}-\theta Q^{-i}+\left(\theta-\theta^{\prime}\right) Q .
$$

Taking maxima over $\left(Q^{-i}, T^{-i}\right) \in \mathfrak{A}^{-i}$ on both sides of this inequality yields

$$
z^{-i}\left(\theta^{\prime}, Q\right) \geq z^{-i}(\theta, Q)+\left(\theta-\theta^{\prime}\right) Q
$$

for all $Q \in[0,1]$. Since $\theta^{\prime} \geq \theta$, the first part of the result follows. Now suppose that

$$
z^{-i}\left(\theta^{\prime}, Q\right)=z^{-i}(\theta, Q)+\left(\theta-\theta^{\prime}\right) Q
$$

for some $Q \in[0,1]$ and $\theta^{\prime}>\theta$. We now show that (39) implies that for any such $Q$ and for any solution $\left(Q^{-i}(\theta, Q), T^{-i}(\theta, Q)\right)$ to the maximization problem that defines $z^{-i}(\theta, Q)$, we have $Q^{-i}(\theta, Q)=Q$. To see this, observe that the trade $\left(Q^{-i}(\theta, Q), T^{-i}(\theta, Q)\right)$ is also feasible in the maximization problem that defines $z^{-i}\left(\theta^{\prime}, Q\right)$. Thus, we must have

$$
z^{-i}\left(\theta^{\prime}, Q\right) \geq T^{-i}(\theta, Q)-\theta^{\prime} Q^{-i}(\theta, Q)=z^{-i}(\theta, Q)+\left(\theta-\theta^{\prime}\right) Q^{-i}(\theta, Q) .
$$

Since $\theta^{\prime}>\theta$ and $Q^{-i}(\theta, Q) \leq Q$, it follows from (39) and (40) that $Q^{-i}(\theta, Q)=$ $Q$, as claimed. Hence the result.

Q.E.D.

Proof of THE SufFICIENCY CONDITION (6): Fix some equilibrium and some buyer $i$, and define the set $\mathfrak{A}^{-i}$ as in (20). We must show that $\mathfrak{A}^{-i}$ is infinite. Observe first that under condition (6), there exists no deviation for any buyer $i$ consisting of the no-trade contract and of a contract $(\tilde{q}, \tilde{t})$ with $\tilde{q}>0$, such that type $\underline{\theta}$ would be worse off trading this contract, while type $\tilde{p}$ would be indifferent between trading it or not, that is, $\tilde{t}=\tilde{p} \tilde{q}$. Indeed, suppose the contrary holds. Then the contract $(\tilde{q}, \tilde{t})$ attracts all types in the interval $\left[p^{*}, \tilde{p}\right)$ and since type $\underline{\theta}$ is the only type below $p^{*}$ in the support of $\mathbf{P}$, no types in the interval $\left[\underline{\theta}, p^{*}\right)$. Because $\tilde{p}$ in (6) can without loss of generality be chosen not to be an atom of $\mathbf{P}$, buyer $i$ 's equilibrium profit must thus at least be

$$
\tilde{q} \int_{\left[p^{*}, \tilde{p}\right]}[v(\theta)-\tilde{p}] d F(\theta),
$$

which is strictly positive by (6). This, however, is impossible, because, by Proposition 1 , each buyer earns zero profit in equilibrium. Hence, type $\underline{\theta}$ must be attracted by any such contract $(\tilde{q}, \tilde{t})$. Since, by Proposition 4 , the equilibrium 
profit $v(\underline{\theta})-\underline{\theta}$ of type $\underline{\theta}$ remains available following buyer $i$ 's deviation, this implies that

$$
v(\underline{\theta})-\underline{\theta} \leq(\tilde{p}-\underline{\theta}) \tilde{q}+z^{-i}(\underline{\theta}, 1-\tilde{q})
$$

for all $\tilde{q} \in(0,1]$, where the function $z^{-i}$ is defined as in (21). Moreover, by Proposition 3 , no contract can be issued at a price strictly above $p^{*}=v(\underline{\theta})$. Thus,

$$
z^{-i}(\underline{\theta}, 1-\tilde{q}) \leq[v(\underline{\theta})-\underline{\theta}](1-\tilde{q})
$$

for all $\tilde{q} \in(0,1]$. Letting $Q \equiv 1-\tilde{q}$ and combining these two inequalities, we obtain the following lower and upper bounds for $z^{-i}(\underline{\theta}, Q)$ :

$$
v(\underline{\theta})-\bar{\theta}+(\bar{\theta}-\underline{\theta}) Q \leq z^{-i}(\underline{\theta}, Q) \leq[v(\underline{\theta})-\underline{\theta}] Q
$$

for all $Q \in[0,1)$, where we have used the fact that there is no loss of generality in assuming that $\tilde{p} \leq \bar{\theta}$ in (6). Since these bounds are strictly increasing in $Q$ and coincide at $Q=1$, the definition of $z^{-i}(\underline{\theta}, \cdot)$ implies that there exists a sequence in $\mathfrak{A}^{-i}$ composed of distinct points that converges to $(1, v(\underline{\theta}))$. The result follows. Q.E.D.

ProOF OF LEMMA 2: Consider an equilibrium of the multiple-buyer multiple-seller nonexclusive competition game with bilateral private contracting. Each buyer $i$ proposes a vector of menus $\left(C_{1}^{i}, \ldots, C_{l}^{i}\right)$ and each seller $j$ optimally chooses from the menus $\left(C_{j}^{1}, \ldots, C_{j}^{n}\right)$ that are designed for her. Suppose now that some type $\theta \neq p^{*}$ of seller $j$ ends up trading an aggregate allocation other than the allocation $(Q(\theta), T(\theta))$ that we showed in Proposition 1 to be the unique aggregate equilibrium allocation of type $\theta$ in the multiplebuyer single-seller nonexclusive competition game with seller $j$. Hence, in this game, at least one buyer $i$ has a strictly better response $\tilde{C}_{j}^{i} \neq C_{j}^{i}$ to the menus $\left(C_{j}^{1}, \ldots, C_{j}^{i-1}, C_{j}^{i+1}, \ldots, C_{j}^{n}\right)$ offered by his competitors, given the equilibrium strategy of seller $j$. Buyer $i$ could thus deviate from $\left(C_{1}^{i}, \ldots, C_{l}^{i}\right)$ in the multiple-buyer multiple-seller nonexclusive competition game with bilateral private contracting by replacing $C_{j}^{i}$ with $\tilde{C}_{j}^{i}$. As menus are private, the sellers other than $i$ would not notice and neither would the buyers other than $j$. Therefore, this deviation is profitable. Hence the result.

Q.E.D.

\section{REFERENCES}

AKerLoF, G. A. (1970): “The Market for 'Lemons': Quality Uncertainty and the Market Mechanism," Quarterly Journal of Economics, 84, 488-500. [1869,1870,1872,1875,1876,1883,1887, 1898]

Ales, L., AND P. MAZIERo (2009): "Non-Exclusive Dynamic Contracts, Competition, and the Limits of Insurance," Unpublished Manuscript, Tepper School of Business, Carnegie Mellon University. Available at http://www.andrew.cmu.edu/user/ales/NEDC.pdf. [1874,1875] 
Aliprantis, C. D., AND K. C. Border (1999): Infinite Dimensional Analysis: A Hitchhiker's Guide. Berlin: Springer-Verlag. [1877,1903]

ARNOTT, R. J., AND J. E. STIGLITZ (1991): "Equilibrium in Competitive Insurance Markets With Moral Hazard," Working Paper 3588, NBER. Available at http://www.nber.org/papers/w3588. [1874]

ATTAR, A., AND A. Chassagnon (2009): “On Moral Hazard and Nonexclusive Contracts," Journal of Mathematical Economics, 45, 511-525. [1874,1893]

AtTAR, A., T. MariotTI, AND F. SalaniÉ (2009): "Non-Exclusive Competition in the Market for Lemons," Working Paper 558, IDEI, Toulouse School of Economics. Available at http:// idei.fr/doc/by/mariotti/Lemon.pdf. [1871,1890,1893]

(2010): "Non-Exclusive Competition Under Adverse Selection," Unpublished Manuscript, Toulouse School of Economics. Available at http://idei.fr/doc/by/mariotti/concave _model27.pdf. [1897,1898]

(2011): "Supplement to 'Nonexclusive Competition in the Market for Lemons': The Exclusive Competition Benchmark," Econometrica Supplemental Material, 79, http://www. econometricsociety.org/ecta/Supmat/8665_extensions.pdf. [1884]

Bernheim, B. D., AND M. D. Whinston (1986): "Menu Auctions, Resource Allocation, and Economic Influence," Quarterly Journal of Economics, 101, 1-31. [1877]

BIAIS, B., AND T. MARIOTTI (2005): "Strategic Liquidity Supply and Security Design," Review of Economic Studies, 72, 615-649. [1873,1878]

Biais, B., D. MARTimort, AND J.-C. Rochet (2000): "Competing Mechanisms in a Common Value Environment,” Econometrica, 68, 799-837. [1873,1874,1877,1891,1894,1896-1898]

BISIN, A., AND P. GOTTARDI (1999): "Competitive Equilibria With Asymmetric Information," Journal of Economic Theory, 87, 1-48. [1875]

(2003): "Competitive Markets for Non-Exclusive Contracts With Adverse Selection: The Role of Entry Fees," Review of Economic Dynamics, 6, 313-338. [1875]

Bisin, A., AND D. GUAITOLI (2004): "Moral Hazard and Nonexclusive Contracts," RAND Journal of Economics, 35, 306-328. [1874]

Bizer, D. S., AND P. M. DEMARZo (1992): “Sequential Banking,” Journal of Political Economy, 100, 41-61. [1874]

BRUNNERMEIER, M. K. (2009): "Deciphering the Liquidity and Credit Crunch 2007-2008," Journal of Economic Perspectives, 23, 77-100. [1894]

CALZOLARI, G. (2004): "Incentive Regulation of Multinational Enterprises," International Economic Review, 45, 257-282. [1873]

CAWLEY, J., AND T. J. PHILIPSON (1999): "An Empirical Examination of Information Barriers to Trade in Insurance," American Economic Review, 89, 827-846. [1870,1899]

CHIAPPORI, P.-A., AND B. SALANIÉ (2000): "Testing for Asymmetric Information in Insurance Markets," Journal of Political Economy, 108, 56-78. [1899]

- (2003): "Testing Contract Theory: A Survey of Some Recent Work," in Advances in Economics and Econometrics: Theory and Applications, Eighth World Congress, Vol. 1, ed. by M. Dewatripont, L. P. Hansen, and S. J. Turnovsky. Cambridge, U.K.: Cambridge University Press, 115-149. [1899]

ChiAPPori, P.-A., B. Jullien, B. SAlanié, AND F. SAlanié (2006): "Asymmetric Information in Insurance: General Testable Implications," RAND Journal of Economics, 37, 783-798. [1899]

Cohen, A., AND P. SiEgelman (2010): "Testing for Adverse Selection in Insurance Markets," Journal of Risk and Insurance, 77, 39-84. [1899]

Dellacherie, C., AND P.-A. Meyer (1982): Probabilities and Potential, Vol. B. Amsterdam: North-Holland. [1900]

DeMarzo, P., AND D. Duffie (1999): “A Liquidity-Based Model of Security Design,” Econometrica, 67, 65-99. [1878]

FinKelstein, A., AND J. M. POTERBA (2002): "Selection Effects in the United Kingdom Individual Annuities Market," The Economic Journal, 112, 28-50. [1870,1899] 
(2004): "Adverse Selection in Insurance Markets: Policyholder Evidence From the U.K. Annuity Market," Journal of Political Economy, 112, 183-208. [1870,1899]

HAN, S. (2006): "Menu Theorems for Bilateral Contracting," Journal of Economic Theory, 131, 157-178. [1895]

Hellwig, M. F. (1983): "On Moral Hazard and Non-Price Equilibria in Competitive Insurance Markets," Discussion Paper 109, Sonderforschungsbereich 21, University of Bonn. [1874]

(1988): "A Note on the Specification of Interfirm Communication in Insurance Markets With Adverse Selection," Journal of Economic Theory, 46, 154-163. [1873]

JAYNES, G. D. (1978): "Equilibria in Monopolistically Competitive Insurance Markets," Journal of Economic Theory, 19, 394-422. [1873]

KAHN, C., AND D. MOOKHERJEE (1998): "Competition and Incentives With Nonexclusive Contracts," RAND Journal of Economics, 29, 443-465. [1874]

KHALIL, F. A., D. MARTIMORT, AND B. PARIGI (2007): "Monitoring a Common Agent: Implications for Financial Contracting," Journal of Economic Theory, 135, 35-67. [1873]

LAFFONT, J.-J., AND J. POUYET (2004): "The Subsidiarity Bias in Regulation," Journal of Public Economics, 88, 255-283. [1873]

MARTIMORT, D. (1992): “Multi-Principaux avec Anti-Sélection," Annales d'Economie et de Statistique, 28, 1-37. [1873]

MARTIMORT, D., AND L. STOLE (2002): “The Revelation and Delegation Principles in Common Agency Games," Econometrica, 70, 1659-1673. [1877,1893]

_ (2003): "Contractual Externalities and Common Agency Equilibria," Advances in Theoretical Economics, 3, Article 4. [1873,1893]

- (2009): "Market Participation under Delegated and Intrinsic Common-Agency Games," RAND Journal of Economics, 40, 78-102. [1873,1885,1889]

Mas-Colell, A., M. D. Whinston, AND J. R. Green (1995): Microeconomic Theory. New York: Oxford University Press. [1879,1887]

Myerson, R. B. (1985): "Analysis of Two Bargaining Problems With Incomplete Information," in Game-Theoretic Models of Bargaining, ed. by A. E. Roth. Cambridge, U.K.: Cambridge University Press, 115-147. [1876,1886]

Parlour, C. A., AND D. J. SePPI (2008): "Limit Order Markets: A Survey," in Handbook of Financial Intermediation and Banking, ed. by A. V. Thakor and A. W. A. Boot. Amsterdam: North-Holland, 63-96. [1894]

Pauly, M. V. (1974): "Overinsurance and Public Provision of Insurance: The Roles of Moral Hazard and Adverse Selection,” Quarterly Journal of Economics, 88, 44-62. [1873]

PECK, J. (1997): "A Note on Competing Mechanisms and the Revelation Principle," Unpublished Manuscript, Ohio State University. Available at http://www.econ.ohio-state.edu/jpeck/reveal. pdf. [1893]

PeTERS, M. (2001): "Common Agency and the Revelation Principle," Econometrica, 69, 1349-1372. [1877,1889,1893]

Peters, M., AND C. Troncoso Valverde (2010): "A Folk Theorem for Competing Mechanisms," Unpublished Manuscript, University of British Columbia. Available at http://montoya. econ.ubc.ca/mike/multiple_agency.pdf. [1895]

PiASER, G. (2006): "The Biais-Martimort-Rochet Equilibrium With Direct Mechanisms," Research Paper Series 33/06, Department of Economics, Università Ca' Foscari Venezia. Available at http://www.dse.unive.it/fileadmin/templates/dse/wp/WP_DSE_Piaser_33_06.pdf. [1874] [1874]

PRAT, A., AND A. Rustichini (2003): “Games Played Through Agents," Econometrica, 71, 989-1026. [1894]

RILEY, J. G. (1985): “Competition With Hidden Knowledge,” Journal of Political Economy, 93, 958-976. [1871]

(2001): "Silver Signals: Twenty-Five Years of Screening and Signaling," Journal of Economic Literature, 39, 432-478. [1871] 
RocheT, J.-C. (1985): "The Taxation Principle and Multi-Time Hamilton-Jacobi Equations," Journal of Mathematical Economics, 14, 113-128. [1901]

RothSCHILD, M., AND J. E. STIGLITZ (1976): "Equilibrium in Competitive Insurance Markets: An Essay on the Economics of Imperfect Information," Quarterly Journal of Economics, 90, 629-649. [1869-1873,1879,1884,1898]

RYSMAN, M. (2007): “An Empirical Analysis of Payment Card Usage," Journal of Industrial Economics, 55, 1-36. [1870]

SAMUELSON, W. (1984): "Bargaining Under Asymmetric Information,” Econometrica, 52, 995-1005. [1876,1886]

Segal, I., AND M. D. Whinston (2003): "Robust Predictions for Bilateral Contracting With Externalities," Econometrica, 71, 757-791. [1877]

StOlE, L. (1990): “Mechanism Design Under Common Agency," Chapter 1 of Ph.D. Dissertation, Massachusetts Institute of Technology. [1873]

YAARI, M. E. (1987): “The Dual Theory of Choice Under Risk," Econometrica, 55, 95-115. [1879]

YAMASHITA, T. (2010): "Mechanism Games With Multiple Principals and Three or More Agents," Econometrica, 78, 791-801. [1895,1896]

Toulouse School of Economics (IDEI, PWRI), Université Toulouse 1 Capitole, 21 Allée de Brienne, 31000 Toulouse, France, and Facoltà di Economia, Università degli Studi di Roma “Tor Vergata," Via Columbia 2, 00133 Roma, Italy; andrea.attar@tse-fr.eu,

Toulouse School of Economics (CNRS, GREMAQ, IDEI), Université Toulouse 1 Capitole, 21 Allée de Brienne, 31000 Toulouse, France; thomas.mariotti@ tse-freu,

$$
\text { and }
$$

Toulouse School of Economics (INRA, LERNA, IDEI), Université Toulouse 1 Capitole, 21 Allée de Brienne, 31000 Toulouse, France; francois.salanie@tse-freu.

Manuscript received June, 2009; final revision received May, 2011. 